APPLIED THERMAL ENGINEERING 133 (2018) 713-726

\title{
Blowdown prediction of a pressure relief valve using a response surface methodology and CFD techniques
}

\author{
Liu Yang ${ }^{\mathrm{a}}$, Chao Wang ${ }^{\mathrm{a}}$, William Dempster ${ }^{\mathrm{b}}$, Xinhai $\mathrm{Yu}^{\mathrm{a}}{ }^{*}$, and Shan-Tung Tu ${ }^{\mathrm{a}}$ \\ ${ }^{\text {a }}$ Key Laboratory of Pressure Systems and Safety (MOE), School of Mechanical Engineering, East China University \\ of Science and Technology, Shanghai 200237, China \\ ${ }^{\mathrm{b}}$ Department of Mechanical and Aerospace Engineering, University of Strathclyde, Glasgow, United Kingdom \\ *Corresponding Author. \\ E-mail address: yxhh@ecust.edu.cn (Xinhai Yu).
}

\begin{abstract}
In this study, parametric assessment of the main geometric design features of a pressure relief valve (PRV) with a backpressure chamber and two adjusting rings was conducted using a response surface methodology. This design approach was established by using computational fluid dynamics (CFD) to model the dynamic performance of the opening and closing of a nuclear power main steam pressure relief valve (NPMS PRV). An experimental facility was established to test the NPMS PRV in accordance with the standard ASME PTC 25, and to validate the CFD model. It was found that the model can accurately simulate the dynamic performance of the NPMS PRV; the difference in blowdown between the simulation and experiment results is found to be below $0.6 \%$. Thus, the model can be used as part of a design analysis tool. The backpressure chamber assisted in the reseating and decreased the blowdown of the NPMS PRV from $18.13 \%$ to $5.50 \%$. The sensitivity to valve geometry was investigated, and an explicit relationship between blowdown and valve geometry was established (with a relative error less than 1\%) using the response surface methodology; this will allow designers to assess the valve settings without the need for a CFD model.
\end{abstract}

\section{Introduction}

The pressure relief valve (PRV) is an indispensable safety component, and in many cases, its installation is a legal requirement in all types of pressure equipment. PRVs open automatically and discharge the contents of the pressure vessel to prevent excess pressure in the system; it is one of the most important devices that prevent overpressure in a nuclear power

*Corresponding Author. $\quad$ E-mail address: yxhh@ecust.edu.cn (Xinhai Yu). 
plant or thermal power plant. However, failures such as the accident that occurred at the Three Mile Island nuclear power plant in the USA [1] do occur, resulting in the need for continued development efforts to ensure effective and reliable valve performance. The operational requirements of safety valves used in nuclear plants are based on ASME III codes; the valves must open within $5 \%$, and close within $10 \%$ of the set pressure. The commonly adopted approach is to test and make corrections; this leads to a long product development time. CFD is an effective method to study the dynamic performance of the valve [2]; the recent developments in CFD techniques allow full dynamic modelling of the valve opening and closing process, and make it possible to establish a direct relationship between design, geometry, and performance. The use of a CFD approach is complex, and transient simulation of safety valves is CPU intensive; this inhibits the application of these approaches. To overcome these issues, a study has been undertaken on a complex safety valve developed for nuclear power plant systems and for steam pressure relief. The valve has upper and lower adjusting rings for setting the opening and closing pressures, and backpressure adjustment to assist valve closure. This results in the valve opening and closing having a multiparametric dependence on the valve's geometrical features, which are difficult to assess and specify; thus, it becomes difficult to ensure consistent valve performance. To investigate more efficient design approaches, a CFD based model of the valve has been combined with a response surface approach to explicitly derive a relationship between blowdown and the main geometrical dimensions associated with the positions of the adjusting elements. The relationship could then be used to assist in the design and settings of the adjusting elements. There have been several attempts to develop analysis methods for safety valve design and operation, primarily driven by the need to ensure effective operation of the valve. In recent years, with the development of CFD techniques, there has been a renewed interest in modelling the dominant valve flow conditions for examining the limitations in the national standards, improving design methods, or ensuring correct operation under conditions in which testing is difficult. For example, Dempster et al. [3] conducted CFD analysis using the commercial code Fluent to determine the characteristics of a conventional gas spring PRV operating at 10-20 bar. The CFD results for mass flow and force agreed well with the experimental data for a certain range of disk lifts. Kim et al. [4] conducted a computational study on a safety valve used for LNG using the two-dimensional, axisymmetric, compressible Navier-Stokes equations to analyze the gas flow between the nozzle exit and valve seat. Ortega et al. [5] developed a dynamic model of the valve based on a spring-mass damper system, formulated the disk force in terms of the momentum change, and used the FLUENT CFD code to analyze the flow coefficient during the discharge of the PRV, with the aim of predicting the overall valve motion. Schmidt et al. [6] modified the simple equation approaches for mass flow rate prediction to account for real gas effects that occur in high-pressure systems. These equations were compared with ISO standard ENISO 4126-1 methods and CFD predictions along with rarely available experimental data on high pressure systems. The study indicated the limitations of the current ISO standards for high-pressure conditions and the effectiveness of the CFD techniques to experimentally explore challenging process conditions. Moncalvo et al. [7] discussed the grid and turbulence model requirements for an accurate prediction of air mass flow rates in two safety valves using the commercial software ANSYS CFX. The results indicate that the degree of discretization was the decisive factor that affects the accuracy of the 
calculations. Improved accuracy was obtained using the shear stress transport (SST) model. Beune et al. [8] also studied the possibility of using multi-mesh CFD based valve model to analyze the dynamic characteristics of high-pressure safety valves. Bassi [9] presented discontinuous Galerkin (DG) discretization of the compressible RANS equations and the $\mathrm{k}-\varepsilon$ turbulence model equations for two-dimensional axisymmetric flows, and used their developed code to investigate the transonic flow in PRVs. The code has been applied to compute the flow in a spring-loaded safety valve at different backpressures and disk lifts. This was used later by Dossena et al. [10] to investigate numerically and experimentally, the effects related to the expansion of different gases in safety relief valves. More recently, Dempster and Elmayyah [11], as well as Alshaikh and Dempster [12], have examined with some success, the ability of two-phase based CFD models to predict the critical flows of air and water through a PRV and improve upon the prediction methods available in the national standard codes. The modelling of safety valve performance primarily requires the ability to capture the dynamic performance during opening and closing. Simplified approaches with experimental validation have recently been reviewed and extended further by Darby et al. $[13,14]$. Similarly, Hős et al. [15] have used simplified modelling approaches to investigate valve stability issues. However, the recent work by Song et al. [16-18] indicates significant progress in the use of the CFD approaches to simulate the dynamic motion of a PRV. They developed a 3-D CFD model in combination with equations for the dynamics of a single degree of freedom system to describe the fluid characteristics and dynamic performance of a spring-loaded PRV; they reported that the blowdown process could be accurately captured. Based on this model, Song [19] also proposed a new process to meet the requirements of butterfly valve design that was characterized by a complex configuration. The work of the current authors [20] has built upon this model using the domain decomposition method (DDM) and the grid predeformation method (GPM) to handle the complex moving disk geometry and the large mesh deformation to further show the credibility of the simulation techniques for complex valve configurations. The existing literature indicates the progress and effectiveness of the CFD techniques for the modelling of common safety valves in single phase steady and unsteady gas applications, and provides promising results for simplified two-phase conditions. Relatively few studies exist for more complex valves, such as those covered in this study, that feature a backpressure chamber; there have been fewer attempts to integrate the CFD techniques into the design process. This study examines the influences of the positions of several adjusting elements (i.e., the adjusting sleeve and adjusting screw of the backpressure chamber, as well as the upper and lower adjusting rings) on the PRV's performance, such as blowdown, and attempts to create a mathematical relationship between the PRV's performance and geometrical configuration. The setting of adjustable elements in such complex valves results in difficult and time-consuming adjustments on site to achieve the desired opening and closing performance of the PRV. This is also particularly challenging for the conditions examined here for an NPMS PRV operating at high temperature and pressure, as repeated opening during initial adjustment result in damage to the sealing surface. This suggests that it is necessary to conduct a detailed investigation on the influence of the adjusting elements to achieve the desired performance of the NPMS PRV. To this end, a three-dimensional CFD based model was established to simulate the dynamic performance of the NPMS PRV, and an experimental facility was developed for the dynamic testing of the NPMS PRV in accordance with the standard ASME PTC 25 [21]. The dynamic performance of the NPMS PRV was recorded, and the simulation 
results were compared with the experimental results to establish the validity of the model. Central composite design (CCD) and a response surface methodology (RSM) were used to evaluate the effect of the positions of the adjusting elements on blowdown. The software Design-Expert $8.05 \mathrm{~b}$ was used to formulate a predictive function and analyze the response surface for blowdown.

\section{Testing of safety relief valve}

In this study, an NPMS PRV provided by Wujiang Dongwu Machinery Co., Ltd, China (Model: 200H2A48Y100C2) was used. Fig. 1 shows the structure of the PRV featuring upper and lower adjusting rings and a backpressure chamber. The positions of the upper and lower rings influence the local flow and pressure conditions at the faces of the disk and disk holder, and allow some control of the opening and closing conditions as well as the setting of the opening pressure.

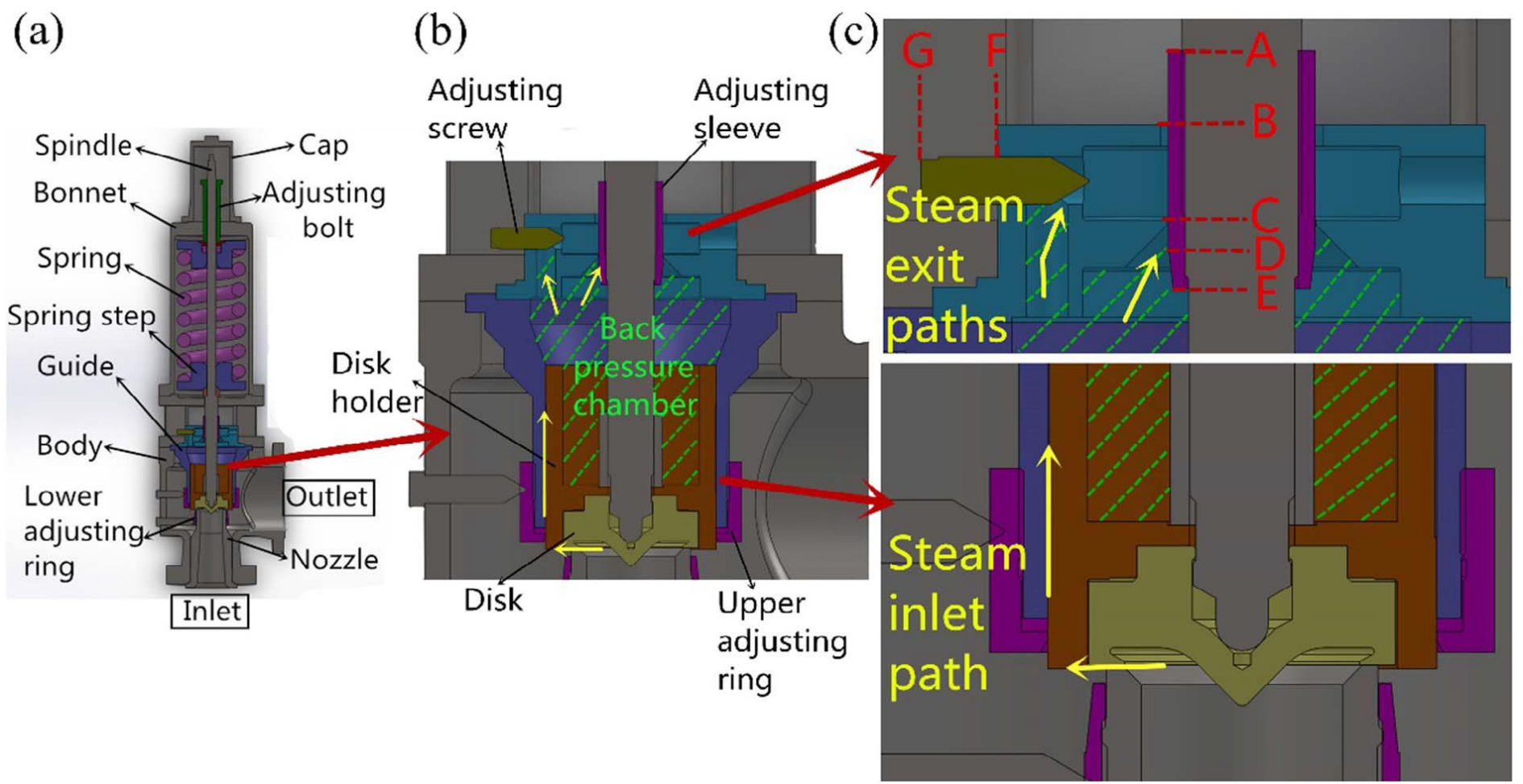

Fig. 1. Schematic representation of NPMS PRV (a), detailed structure of back pressure chamber of NPMS PRV (b), the positions of points of A-G and the inlet and exit paths of steam (c).The back pressure chamber is marked with green dotted line. (For interpretation of the references to colour in this figure legend, the reader is referred to the web version of this article.)

The void at the rear of the disk holder forms a backpressure chamber, where the pressure contributes to a downward force which can assist in the effective closing of the valve. The pressure in the backpressure chamber is generated from the 
inlet flow from the disk face through a narrow channel between the disk holder and disk guide (blue surface in Fig. 1), and the exit flow from two possible paths: (i) a sleeve attached via a thread to the valve spindle; when the sleeve is adjusted, the exit flow area between the sleeve and the backpressure chamber end cap changes; (ii) a side vent hole where the exit flow area is adjusted by a screw (see Fig. 1). The backpressure chamber vents into the secondary chamber which is open to the atmosphere. The minimum opening of the adjusting sleeve is achieved when the disk reaches the rated lift and points $\mathrm{C}$ and D meet (see Fig. 1). The maximum opening is achieved when the NPMS PRV reseats and points C and E meet. Practically, the exit flow area of the backpressure chamber can be adjusted by controlling the vertical position of the adjusting sleeve above the top face of the end cap, i.e., distance AB in Fig. 1. In addition, the degree of insertion of the adjusting screw controls the alternative path, which is determined by the screw insertion depth (distance FG in Fig. 1). The distances AB and FG are 40 and $33 \mathrm{~mm}$, respectively. When the NPMS PRV pops up, steam flows into the backpressure chamber through the gap between the disk holder and guide, generating an additional force on the disk.

The experimental set-up shown in Fig. 2 was established in Wujiang Dongwu Machinery Co., Ltd, China. The experimental method complies with ASME PTC 25 guidelines. A supercritical pressure boiler supplies saturated steam to a storage vessel, which stores the high-pressure steam. The PRV for testing was mounted on the test vessel. During the test, the pressures in the storage vessel and test vessel were slowly increased to $90 \%$ of the expected set pressure of the NPMS PRV. Then, the control valve upstream of the test vessel was quickly opened to introduce steam from the storage vessel into the test vessel, causing an increase in pressure in the test vessel and opening of the PRV.

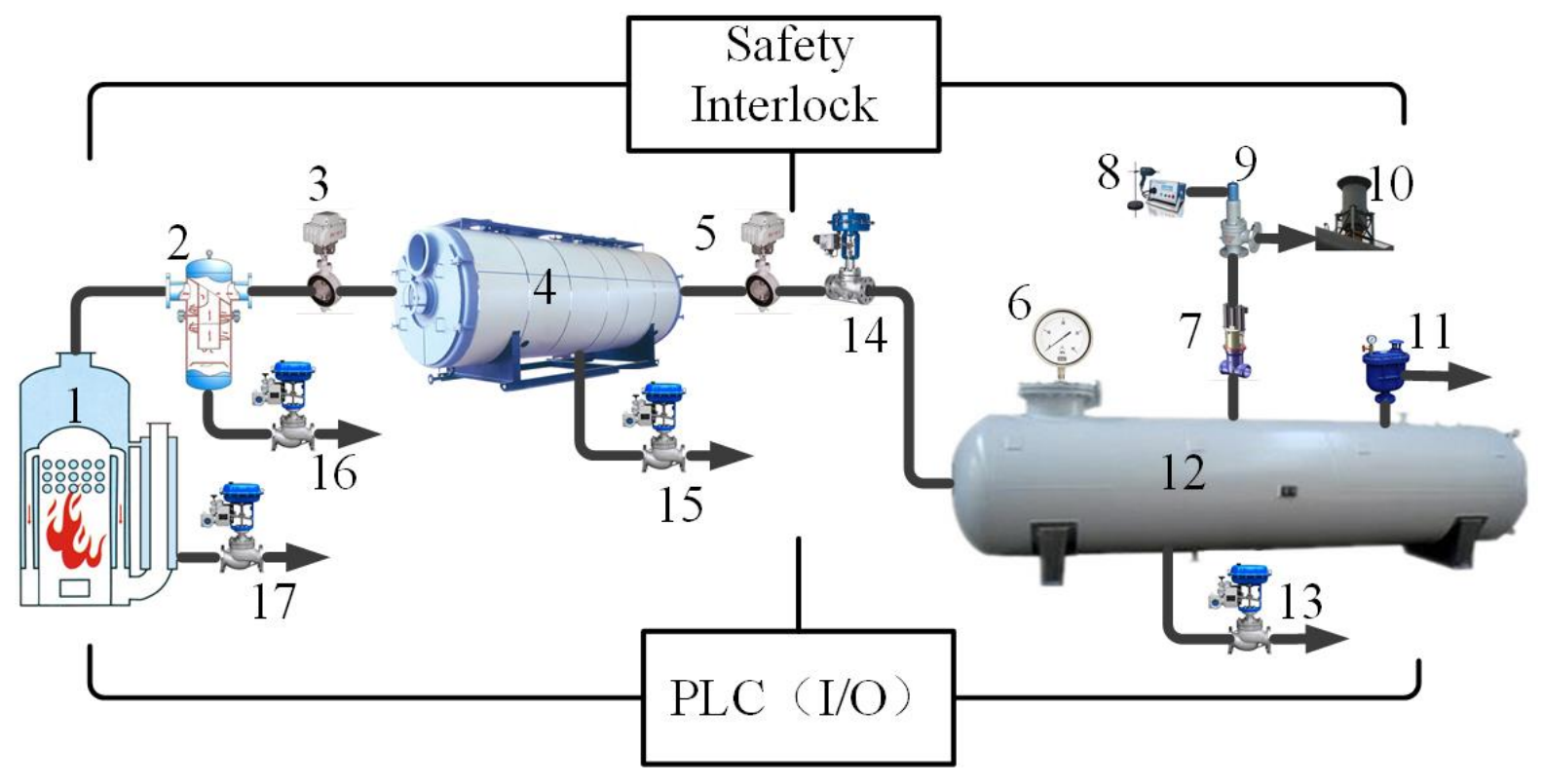

Fig. 2. NPMS PRV experimental set-up: 1. supercritical boiler; 2. steam separator; 3. on-off valve; 4. storage vessel; 5. on-off valve; 6 . pressure measuring system; 7. isolating valve; 8. lift testing device; 9. measured PRV; 10. Silencer; 11. quick exhausting valve; 12 . testing vessel; 13-17. control valves. 
The pressure in the test vessel was stabilized at the relieving pressure (7.26 MPa) by the control valve for several seconds, and then the control valve was shut off, causing a reduction in the pressure and allowing the NPMS PRV to reseat. The disk lift, the pressure in the test vessel, and the pertinent characteristics of the tested PRV were observed and recorded. The measurement accuracies of the pressure transmitter (BP201/501Z, Hefei Sentech Sensing Instruments Co., Ltd.) and displacement transducer (ZS-LD200, OMRON) are $\pm 0.5 \%$ and $\pm 0.2 \%$, respectively. The PLC (S7-300, Siemens) collected the data with a time resolution of $10 \mathrm{~ms}$. The process was checked using a high-speed camera (Motion Xtra N4, IDT). Fig. 3 shows an image of the NPMS PRV in the fully open condition during the performance testing. A silencer was connected to the outlet of the NPMS PRV to reduce the discharge noise and to ensure a sufficiently low backpressure.

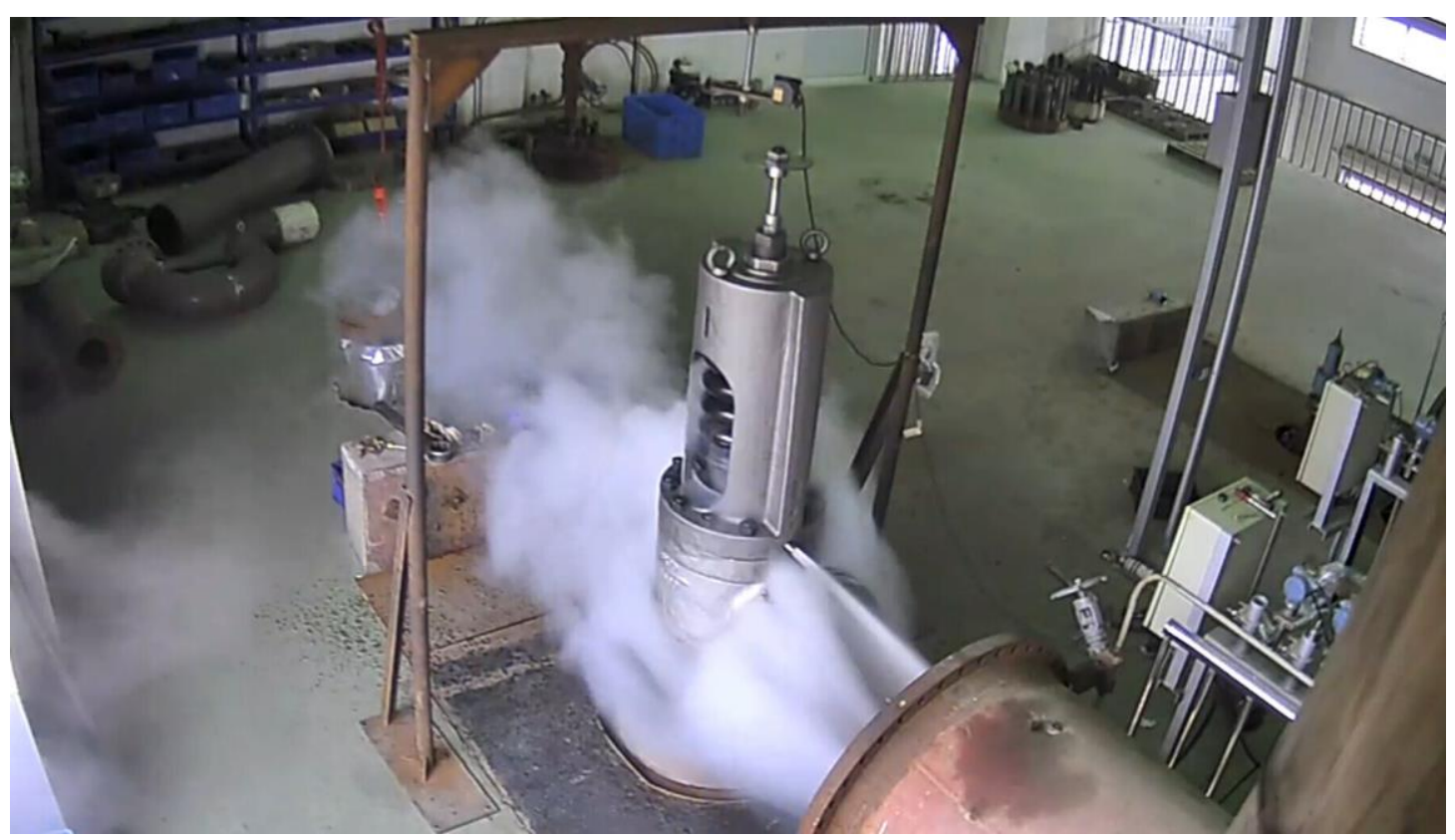

Fig. 3. Photo of a NPMS PRV fully open during performance test.

\section{Model and simulation analysis}

The simulation was performed using the commercial software ANSYS CFX 14.0. A Navier Stokes (RANS) formulation was used in conjunction with the SST turbulence model for turbulence closure [7]. High resolution, second order backward Euler, and high-resolution options were used for the advection scheme, transient scheme, and turbulence discretization, respectively. Standard wall functions were used to avoid the need to form grids on the boundary layer. The convergence criteria were set such that the residual root mean square (RMS) error values were strictly below $10-5$. To reduce the number of grid cells and reduce calculation time, a half-symmetrical model and variable time steps were used in the simulation. By using moving meshes (including the disk, disk holder, and the adjusting sleeve) for the simulation, the structural meshes 
were generated to ensure that there is no element with a negative volume or poor quality at any iteration step. The entire flow field model was divided into several domains while using the ICEM mesh methodology, as shown in Fig. 4. The volume of the test vessel was taken as $10 \mathrm{~m}^{3}$, which is equal to the volume used in the experiment. Dry saturated steam was used as the working medium.

\subsection{Valve disk dynamics}

The displacements of the moving parts were determined using a single degree of freedom model for the valve motion. These are expressed by Eqs. (1)-(4); the mass of the moving parts is defined by Eq. (2). The details of the derivation process are shown in the Appendix :Supplementary Materials.

$$
\begin{gathered}
y_{t+\Delta t}=\frac{F_{\text {flow }}+F_{c}-F_{0}-G_{\text {disk }}-F_{0.5}+\frac{m_{\text {movable }}}{\Delta t^{2}} y_{t}+\frac{m_{\text {movable }}}{\Delta t} \dot{y}_{t}}{\frac{m_{\text {movable }}}{\Delta t^{2}}+k_{\text {spring }}} \\
m_{\text {movable }}=0.5 m_{\text {spring }}+m_{\text {spindle }}+m_{\text {disk-hoder }}+m_{\text {disk }}+m_{\text {bearing-seating }}+m_{\text {adjusting sleeve }} \\
G_{\text {disk }}=\left(m_{\text {spring }}+m_{\text {spindle }}+m_{\text {disk-hoder }}+m_{\text {disk }}+m_{\text {bearing }}+2 m_{\text {bearing-seating }}+m_{\text {adjusting sleeve }}\right) \times g \\
F_{0}=\Delta y_{0} \cdot k_{\text {spring }}
\end{gathered}
$$

where $m_{\text {spring }}, m_{\text {spindle }}, m_{\text {disk-holder, }}, m_{\text {disk }}, m_{\text {bearing }}, m_{\text {bearing-seating }}$ and $m_{\text {adjusting sleeve }}$ are the masses of the spring, spindle, disk holder, disk, bearing, bearing seating and adjusting sleeve, respectively. $\dot{y}_{\mathrm{t}}$ is the disk velocity; $y_{\mathrm{t}}$ is the disk lift; $F_{\text {flow }}$ is the force applied by the flowing fluid; $F_{\mathrm{c}}$ is the force on the moving parts imposed by the accumulated steam in the back pressure chamber; $\Delta t$ is the time step determined in CFX; $k_{\text {spring }}$ is the stiffness of spring; $\Delta y_{0}$ is the spring initial compression; $F_{0.5}=$ $0.5 \mathrm{~mm} \times k_{\text {spring. }}$. An initial lift of $0.5 \mathrm{~mm}$ is used at the first calculation step to establish a continuous flow field. ANSYS CFX expression language (CEL) is used to solve Eqs. (1)-(4) and couple the equations to the CFD simulation.

\subsection{Domain decomposition and grid generation}

The entire domain was connected by several general grid interfaces (GGIs). DDM and GPM were adopted to generate the structural meshes easily, and to handle the complex shape of the flexible disk and the large mesh deformation that occurs when the disk is moving. Fig. 4 shows the mesh model of the domains. The computational mesh in the crucial disk region at the minimum $(0.5 \mathrm{~mm})$ and maximum $(30 \mathrm{~mm})$ openings are shown in Fig. 4. To ensure simulation accuracy, grid independency tests were conducted. Theoretically, grid independency is reached when further refinement of the computational grid cannot change the numerical solution significantly. The impact of mesh fineness was investigated by determining the lifting force of the PRV, which has a significant influence on the dynamic performance of the disk and the 
overall simulation accuracy. Different mesh densities were generated to examine the changes in the lifting force. For a grid size corresponding to 1.6 million cells, no change in lifting force was found with the change in mesh density, indicating that the calculation of lifting force is relatively independent of mesh density. This grid size was chosen for the transient study.

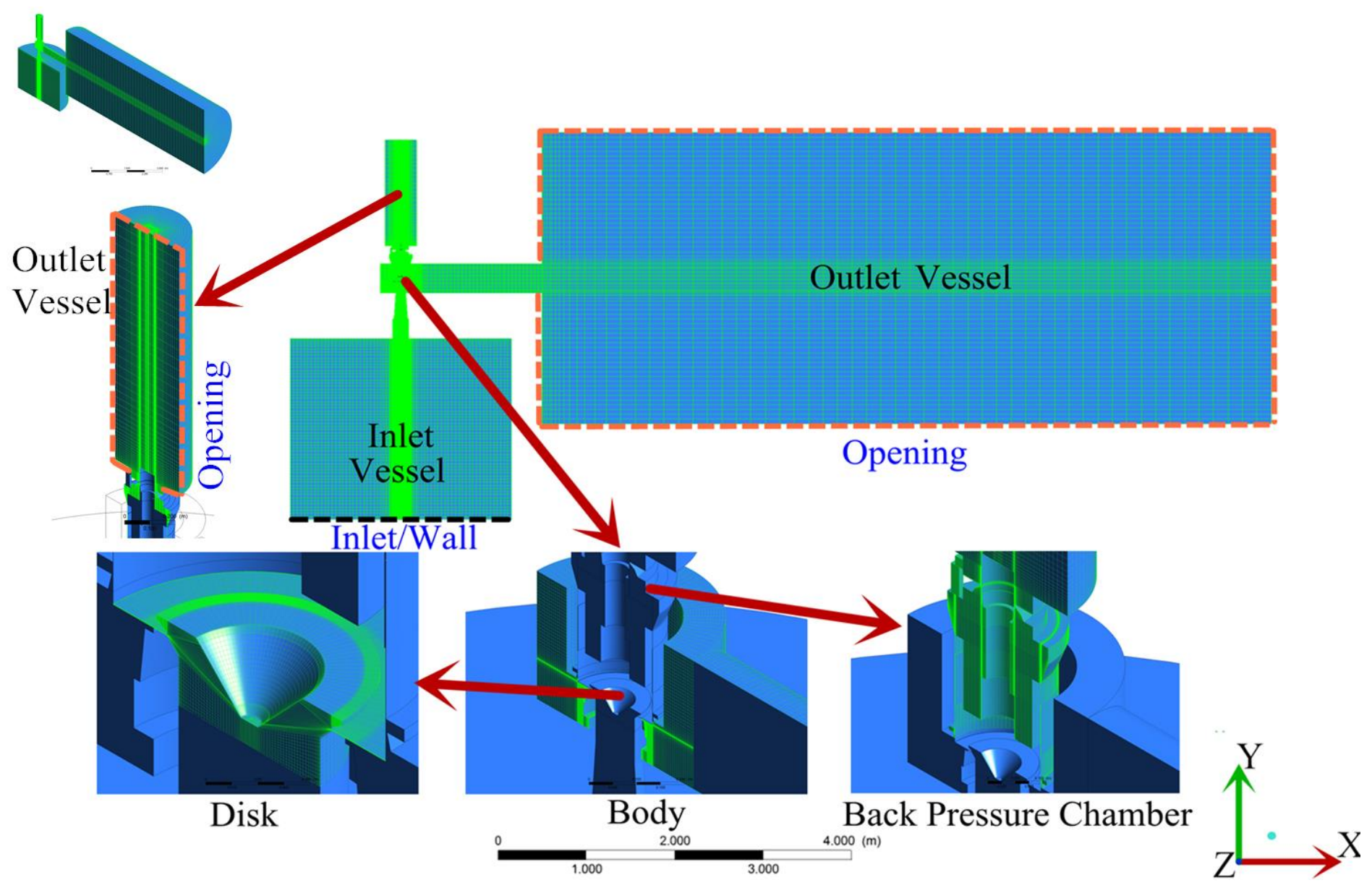

Fig. 4. Mesh model and position relationship between each domain.

\subsection{Boundary conditions}

Fig. 4 shows the computational mesh and boundary conditions. The disk, adjusting sleeve, and disk holder can move in the y direction as given by Eq. (1). The reference pressure over all the domains was defined as the atmospheric pressure. The initial gauge pressure in the test vessel domain was set as $7.2 \mathrm{MPa}$, which is equal to the set pressure of the NPMS PRV. The inlet condition of the test vessel was set at a constant gauge pressure of 7.26 MPa (relieving pressure). The initial pressures in the other domains were set as $0 \mathrm{MPa}$. During the dynamic simulation, the inlet to the test vessel was changed from a constant pressure (7.26 MPa) condition to a wall condition. In this manner, the dynamic simulation was conducted considering the action of the test vessel control valve, which closed on the opening of the PRV valve during the experiment. 


\section{Design methodology}

\subsection{Central composite design}

In this study, a quadratic model using RSM, suggested by the software Design-Expert 8.05b, was used for design and data analysis. The effects of four independent numerical variables (at five levels) on the blowdown were investigated using CCD. The four variables are the distance between points A and B , Fig 1c, (E, reflecting the position of the adjusting sleeve), distance between points $\mathrm{F}$ and $\mathrm{G}$ (W, corresponding to the position of the adjusting screw), distance between the upper adjusting ring and sealing face (U), and distance between the lower adjusting ring and sealing face (L). For the five-level $\mathrm{CCD}$, a total of 30 numerical runs were conducted together with five replications at the centre points. In the RSM, blowdown was defined as the response and objective of the design and simulation modelling. The independent variables and their coded/actual levels used in this study are listed in Table 1. All the defined numerical variables were transformed to the coded form using Eq. (5).

$$
X_{i}=\frac{x_{i}-x_{0}}{\Delta x}
$$

where $X_{\mathrm{i}}$ describes the coded value of the $i_{\mathrm{th}}$ independent factor which is dimensionless. The actual value is defined as $x_{\mathrm{i}} . x_{0}$ is the center point actual value and $\Delta x$ refers to the step change of the $i_{\text {th }}$ variable [22].

\section{Table 1}

Levels of variables chosen for central composite design.

\begin{tabular}{|c|c|c|c|c|c|c|c|c|}
\hline \multirow[t]{2}{*}{ Variable } & \multirow[t]{2}{*}{ Symbol } & \multicolumn{2}{|c|}{ Code } & \multicolumn{5}{|c|}{ Level } \\
\hline & & Coded $^{\mathrm{a}}$ & True & -2 & -1 & 0 & 1 & 2 \\
\hline Distance between points A and B (mm) & E & $X_{1}$ & $x_{1}$ & 35 & 44 & 53 & 62 & 71 \\
\hline Distance between points $\mathrm{F}$ and $\mathrm{G}(\mathrm{mm})$ & $W$ & $X_{2}$ & $x_{2}$ & 36.5 & 40 & 43.5 & 47 & 50.5 \\
\hline $\begin{array}{l}\text { Distance between the upper adjusting } \\
\text { ring and the sealing face (mm) }\end{array}$ & $U$ & $X_{3}$ & $x_{3}$ & 3 & 6 & 9 & 12 & 15 \\
\hline $\begin{array}{l}\text { Distance between the lower adjusting } \\
\text { ring and the sealing face ( } \mathrm{mm})\end{array}$ & $L$ & $X_{4}$ & $x_{4}$ & 1.25 & 2.5 & 3.75 & 5 & 6.25 \\
\hline
\end{tabular}

\subsection{Response surface methodology}

After the response data were obtained from the numerical runs, RSM was employed for analysis of the results. According to the model provided by the response surface analysis software, a quadratic response surface equation was selected, which can be expressed as [23]: 


$$
Y=\beta_{0}+\sum_{i=1}^{n} \beta_{\mathrm{i}} x_{i}+\sum_{i=1}^{n} \beta_{\mathrm{ii}} x_{i}^{2}+\sum_{i=1}^{n} \sum_{j=i}^{n} \beta_{\mathrm{ij}} x_{i} x_{j}+\varepsilon
$$

where $\mathrm{Y}$ is the response (or objective function); $\mathrm{x}_{\mathrm{i}}$ is the independent variable; $\beta_{\mathrm{i}}, \beta_{\mathrm{ii}}$, and $\beta_{\mathrm{ij}}$ represent the regression coefficients of the first degree item, second-degree item, and interaction terms, respectively, $\mathrm{n}$ is the number of factors; $\varepsilon$ is the random error, mainly arising from experimental error and fitting error. In addition, to assess the suitability of the proposed model, an analysis of variance (ANOVA) was performed. The coefficients of determination (R2 and R2 adj) represent the estimates of the goodness of fit for the suggested model. These values can be determined using the following equations [24].

$$
\begin{gathered}
R^{2}=1-\frac{S S_{\text {residual }}}{S S_{\text {model }}+S S_{\text {residual }}} \\
R_{\text {adj }}^{2}=1-\frac{S S_{\text {residual }} / D F_{\text {residual }}}{\left(S S_{\text {model }}+S S_{\text {residual }}\right) /\left(D F_{\text {model }}+D F_{\text {residual }}\right)}
\end{gathered}
$$

In these equations, SS is the sum of squares, and DF is the degree of freedom. Eqs. (9) and (10) were used to check the model's adequate precision ratio (AP) to determine the statistical importance of the model [25].

$$
\begin{gathered}
\text { Adequate Precision }=\frac{\max (Y)-\min (Y)}{\sqrt{\overline{\mathrm{V}}(\mathrm{Y})}} \\
\overline{\mathrm{V}}(\mathrm{Y})=\frac{1}{n} \sum_{i=1}^{n} \overline{\mathrm{V}}(\mathrm{Y})=\frac{p \sigma^{2}}{n}
\end{gathered}
$$

where $Y$ is the predicted response; $p$ represents the number of model parameters; residual mean square is described as $\sigma^{2} ; n$ is the number of experiments (simulations).

\section{Results and discussion}

\subsection{Verification of simulation results}

The experimental and simulation results are shown in Figs. 5 and 6. The values of U, L, W, and E are 3, 0.75, 33, and 40 $\mathrm{mm}$, respectively. The simulation results are in good agreement with the experimental results. The reseating pressures from the experiment and simulation are 6.59 and $6.63 \mathrm{MPa}$, respectively. The difference in blowdown between the simulation and experimental results is below $0.6 \%$. As shown in Fig. 5a Within $41 \mathrm{~ms}$, the valve opened rapidly from the initial lift of 
$0.5 \mathrm{~mm}$ to the maximum lift of $30 \mathrm{~mm}$, and the resultant force (in simulation) acting on the disk (including lifting force, component gravity, Fc, and spring force) increased sharply from 0 to 12,500 N (see Fig. 6). As shown in Fig. 5b, for the simulation, the pressure in the test vessel is higher than 7.26 MPa before $50 \mathrm{~ms}$, because the model imposed a sudden increase in the inlet pressure in the test vessel from 7.2 to 7.26 MPa, as explained in Section 3.3.
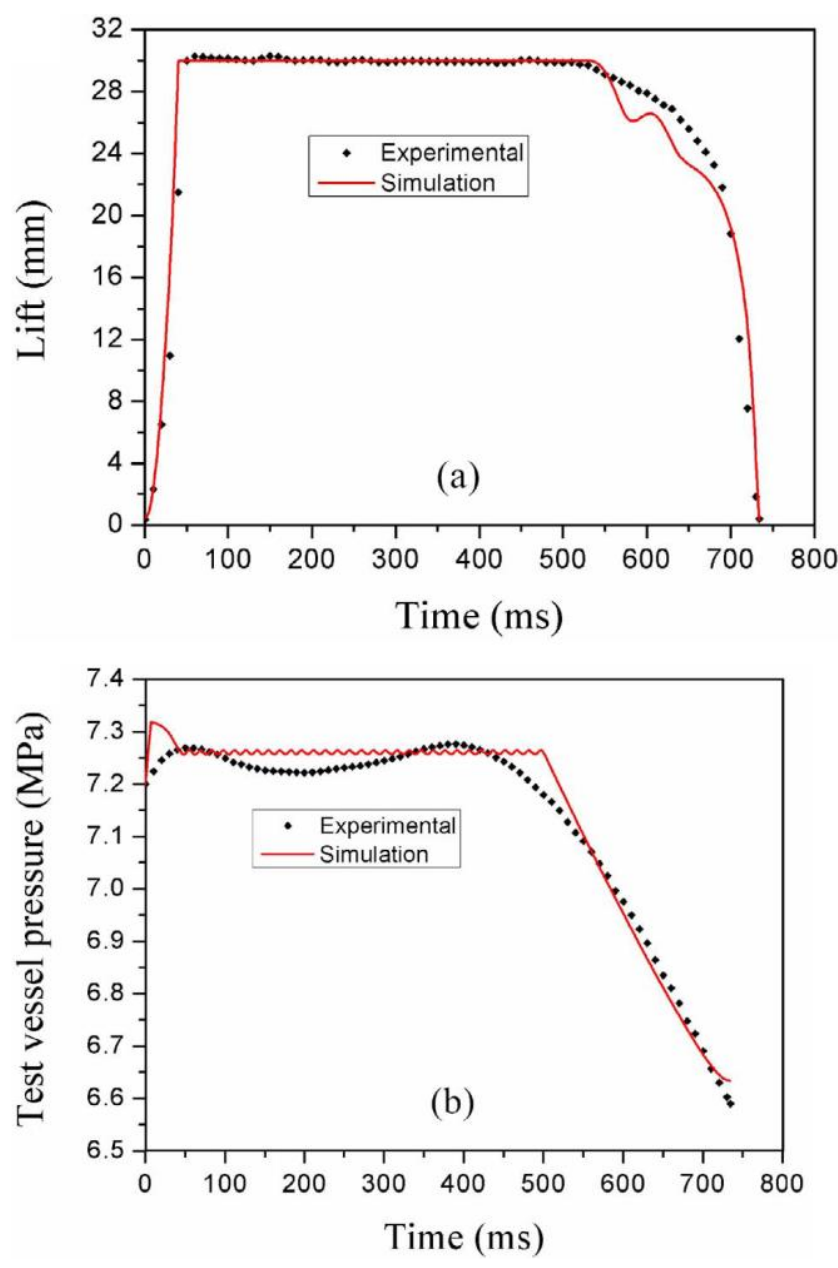

Fig. 5. The lift (a) and inlet vessel pressure (b) as a function of discharge time of NPMS PRV $\left(k_{\text {spring }}=2027.8 \mathrm{~N} \mathrm{~mm}^{-1}\right.$; throat size of $115 \mathrm{~mm}$ in diameter; $U, L, W$, and $E$ are $3,0.75,33$, and $40 \mathrm{~mm}$, respectively; dry saturated steam).

The lift remained at a stable value of 30mm during the period $41-526 \mathrm{~ms}$ because of the presence of a stop for the lift in the PRV. When the disk reached the rated lift, the predicted test vessel pressure stabilized at $7.26 \mathrm{MPa}$, whereas it varied in the range of 7.2-7.3 MPa in the experiment. This variation is attributed to the limited accuracy of the control valve upstream of the test vessel during the experiment. When the steam that is fed to the test vessel was shut off at $500 \mathrm{~ms}$, the lifting force declined gradually with the decrease in the test vessel pressure (see Fig. 6). At $526 \mathrm{~ms}$, when the resultant force on the disk turned negative, the PRV started to close. Because of the interaction between the lifting force and spring force during the 
closing process, an alternating upward and downward net force was generated on the disk, as shown in Fig. 6. This alternating force caused slight fluttering during the closing of the PRV (see Fig. 5a). During the test, the damping effect caused by the friction between the moving disk and fixed components could alleviate the fluttering. The friction exhibited a trivial effect on the blowdown, and hence it was omitted in the simulation.

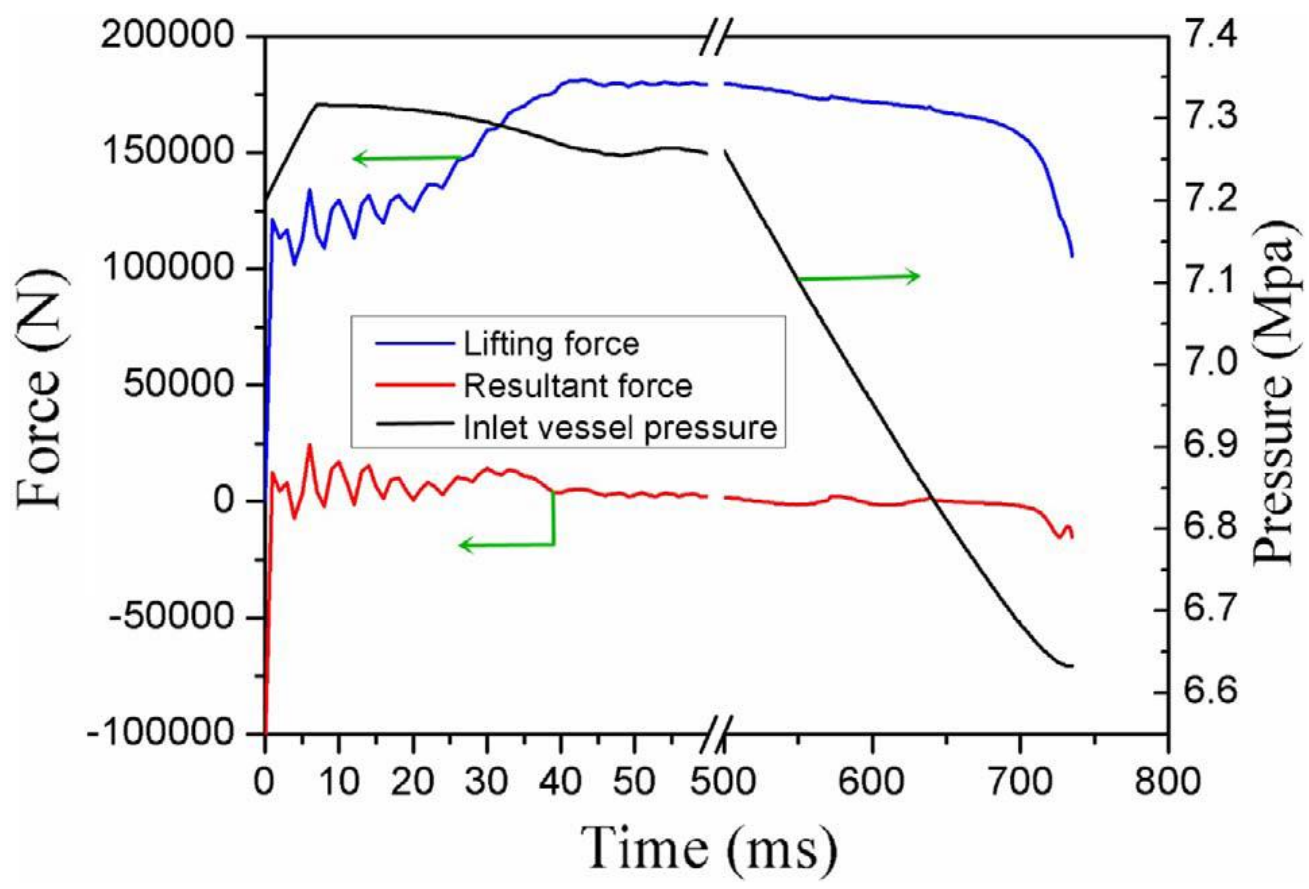

Fig. 6. The lifting force, resultant force and inlet vessel pressure as a function of discharge time of NPMS PRV (the vertical upward force along the spindle is positive, $\mathrm{k}_{\text {spring }}=2027.8 \mathrm{Nmm}^{-1}$; throat size of $115 \mathrm{~mm}$ in diameter; $\mathrm{U}, \mathrm{L}, \mathrm{W}$, and $\mathrm{E}$ are 3 , $0.75,33$ and $40 \mathrm{~mm}$, respectively; dry saturated steam).

\subsection{Performance comparison between PRVs with and without back pressure chamber}

The dynamic performance of the PRV, with and without the backpressure chamber, were compared by simulation; the results are shown in Fig. 7. The PRV with the backpressure chamber started to close at 7.001 MPa, which is $0.435 \mathrm{MPa}$ higher than that in the case without a backpressure chamber. This is because steam accumulates in the backpressure chamber, and generates a downward force on the moving parts of the PRV during discharge; this reduces the resultant upward force, and leads to a higher reseating pressure. For the settings shown in Fig. 7, the reseating pressures for the cases without and with the backpressure chamber were 5.895 and $6.801 \mathrm{MPa}$, respectively, indicating a decrease in blowdown from $18.13 \%$ to $5.50 \%$. Because of this decrease, the ASME III PRV setting requirements are satisfied. Figs. 8 and 9 show the Mach numbers and velocity vectors at the seat and in the backpressure chamber region during discharge at 5, 25, 200, and $710 \mathrm{ms,}$ 
which are representative of the conditions during the initial opening, quick opening, stable discharge, and the period close to reseating, respectively.
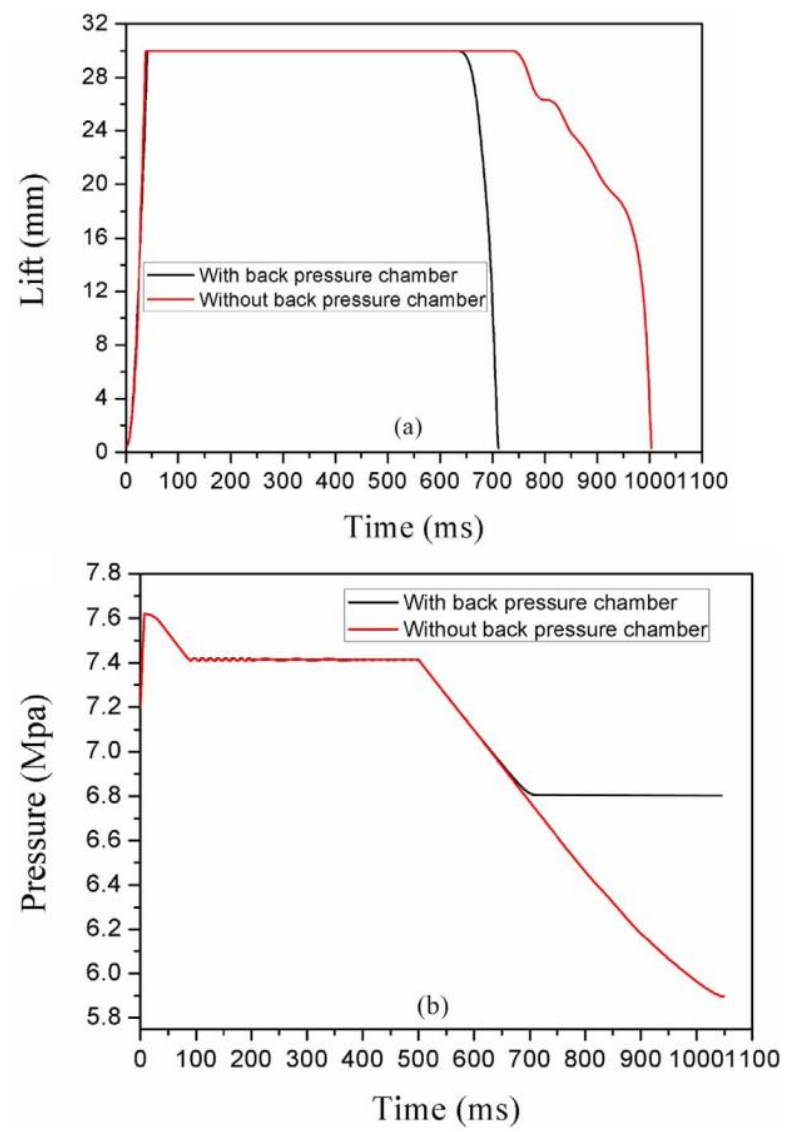

Fig. 7. The influence of back pressure chamber on the dynamic performance: (a) lift and (b) inlet vessel pressure (with a back pressure chamber; U, L, W, and E are 9, 3.75, 43.5 and $53 \mathrm{~mm}$, respectively; dry saturated steam).

It can be seen from Fig. 8 that the steam accelerates as it flows from the test vessel to the valve inlet. The flow turns supersonic as it is rapidly accelerated through the seat region. At $5 \mathrm{~ms}$, two supersonic flow regions occur in the narrow gap between the disk and lower adjusting ring (Mach 3.8), as well as in the region below the upper adjusting ring (Mach 3.4). The positive pressure between the upper adjusting ring and disk seat creates a flow of steam toward the backpressure chamber (see Fig. 9(a), (e), (g), and (f)). At 25 ms, steam starts flowing into the backpressure chamber with an increase in lift (see Fig. 9(b) and (h)). The transient inflow results in a vortex at the inlet of the backpressure chamber. The maximum velocity (Mach 2.90) is found below the upper adjusting ring. The flow rate in the gap between the guide and disk holder is $0.121 \mathrm{~kg} \mathrm{~s}^{-1}$, and the flow rates through the adjusting screw and adjusting sleeve are $0.017 \mathrm{~kg} \mathrm{~s}^{-1}$ and $0.061 \mathrm{~kg} \mathrm{~s}^{-1}$, respectively; i.e., there is net mass flow into the backpressure chamber. At $200 \mathrm{~ms}$, the disk rises to the highest value of 30 mm. Two high velocity zones (Mach 3.37), one at the gap between the disk holder and lower adjusting ring, and the other at the gap between the upper and lower adjusting rings, can be observed. The flow rate in the gap between the guide and 
disk holder is $0.369 \mathrm{~kg} \mathrm{~s}^{-1}$, and the flow rates through the adjusting screw and adjusting sleeve are $0.051 \mathrm{~kg} \mathrm{~s}^{-1}$ and 0.318 $\mathrm{kg} \mathrm{s}^{-1}$, respectively; i.e., the inflow and outflow are balanced. A vortex appears at the bottom of the backpressure chamber, as shown in Fig. 9(c) and (i). The pressure in the backpressure chamber achieves a stable value of 0.238 MPa (see Fig. 10) owing to the balanced mass flow. The backpressure is $3.31 \%$ of the setting pressure, and results in a downward force Fc of $3554 \mathrm{~N}$, which is $36.3 \%$ of the lifting force, when the steam that is fed to the chamber is shut off at $500 \mathrm{~ms}$; this is shown in Fig. 10. It can be seen that the PRV starts to close at $633 \mathrm{~ms}$. The pressure in the backpressure chamber decreases slightly during the period 500-644 ms (see Fig. 10). As shown in Fig. 1, the steam flowing through the gap between the disk holder and guide, together with the discharging steam through the adjusting screw and sleeve, determine the pressure in the backpressure chamber. During the period 500-644 ms, the flow rate in the gap between the guide and disk holder changes from $0.369 \mathrm{~kg} \mathrm{~s}^{-1}$ to $0.349 \mathrm{~kg} \mathrm{~s}^{-1}$, and the flow rates through the adjusting screw and adjusting sleeve change from $0.051 \mathrm{~kg}$ $\mathrm{s}^{-1}$ and $0.318 \mathrm{~kg} \mathrm{~s}^{-1}$ to 0.048 and $0.301 \mathrm{~kg} \mathrm{~s}^{-1}$, respectively. The flow rate of the steam that is fed to the chamber is equal to that of the discharging steam at $500 \mathrm{~ms}$ and $644 \mathrm{~ms}$. Then, the pressure in the backpressure chamber increases and achieves a maximum value of $0.23 \mathrm{MPa}$ at $676 \mathrm{~ms}$. This is because the outlet gap of the backpressure chamber decreases with the decrease in disk lift during the period 650-676 ms, resulting in a drop in the effluent stream flow rate. Simultaneously, the inlet pressure in the backpressure chamber and the gap between the guide and disk holder do not change significantly, suggesting that steam is being fed at a constant mass flow rate to the chamber. Subsequently, the pressure in the backpressure chamber decreases to zero at $750 \mathrm{~ms}$; i.e., the backpressure chamber maintains a positive pressure and discharges the steam to the atmosphere after the PRV reseats. When the PRV reseats, the flow of steam through the gap between the disk holder and guide is shut off. However, the resulting exit flow rate of steam from the chamber is relatively small because of the effective flow areas related to the adjusting screw and adjusting sleeve; this results in a slow decay of the pressure in the backpressure chamber after the closure of the PRV. Thus, a considerable force is maintained on the disk in the direction opposite to the lifting force during the reseating of the PRV. It is apparent that the reseating of the PRV can be assisted by the addition of the backpressure chamber, and that it can be adjusted by controlling the mass flow rates to and from the chamber. To further illustrate the role of the backpressure chamber in the adjustment of reseating pressure, the case at $710 \mathrm{~ms}$ is taken as an example. At $710 \mathrm{~ms}$, the Mach number at the gap between the disk holder and lower adjusting ring is 4.04 . The flow rate in the gap between the guide and disk holder is $0.012 \mathrm{~kg} \mathrm{~s}^{-1}$, and the flow rates through the adjusting screw and the sleeve are $0.032 \mathrm{~kg} \mathrm{~s}^{-1}$ and $0.025 \mathrm{~kg} \mathrm{~s}^{-1}$, respectively. At this moment, the pressure in the backpressure chamber is as high as $0.047 \mathrm{MPa}$, which provides a force of $1640 \mathrm{~N}$ on the disk ( $66.2 \%$ of the lifting force). Steam temperature contours in the backpressure chamber are shown in Fig. 11. The steam temperature distribution in this region has a close relationship with the displacement of the valve disk. At the initial opening of the PRV (5 ms), the hightemperature steam is mainly concentrated at the nozzle, and only a small amount of steam is discharged out. During the quick opening of the PRV (25 ms), the steam discharges rapidly. The steam temperature in the valve body region changes to a value close to that in the disk region. A significant increase in steam temperature can be observed at the inlet of the backpressure chamber. The steam temperature in the region between the upper and lower adjusting rings is much lower than 
that in the other regions, because the enthalpy of the steam is converted into kinetic energy when the steam is accelerated through the nozzle [26]. At $200 \mathrm{~ms}$, when the PRV reaches a stable discharge level, the steam temperature in the backpressure chamber reaches the highest value of $560 \mathrm{~K}$, and the steam temperature at the throat decreases to $510 \mathrm{~K}$. At $710 \mathrm{~ms}$, when the PRV is in the process of reseating, the steam temperature in the valve body region decreases, because the amount of steam discharged from the PRV decreases.
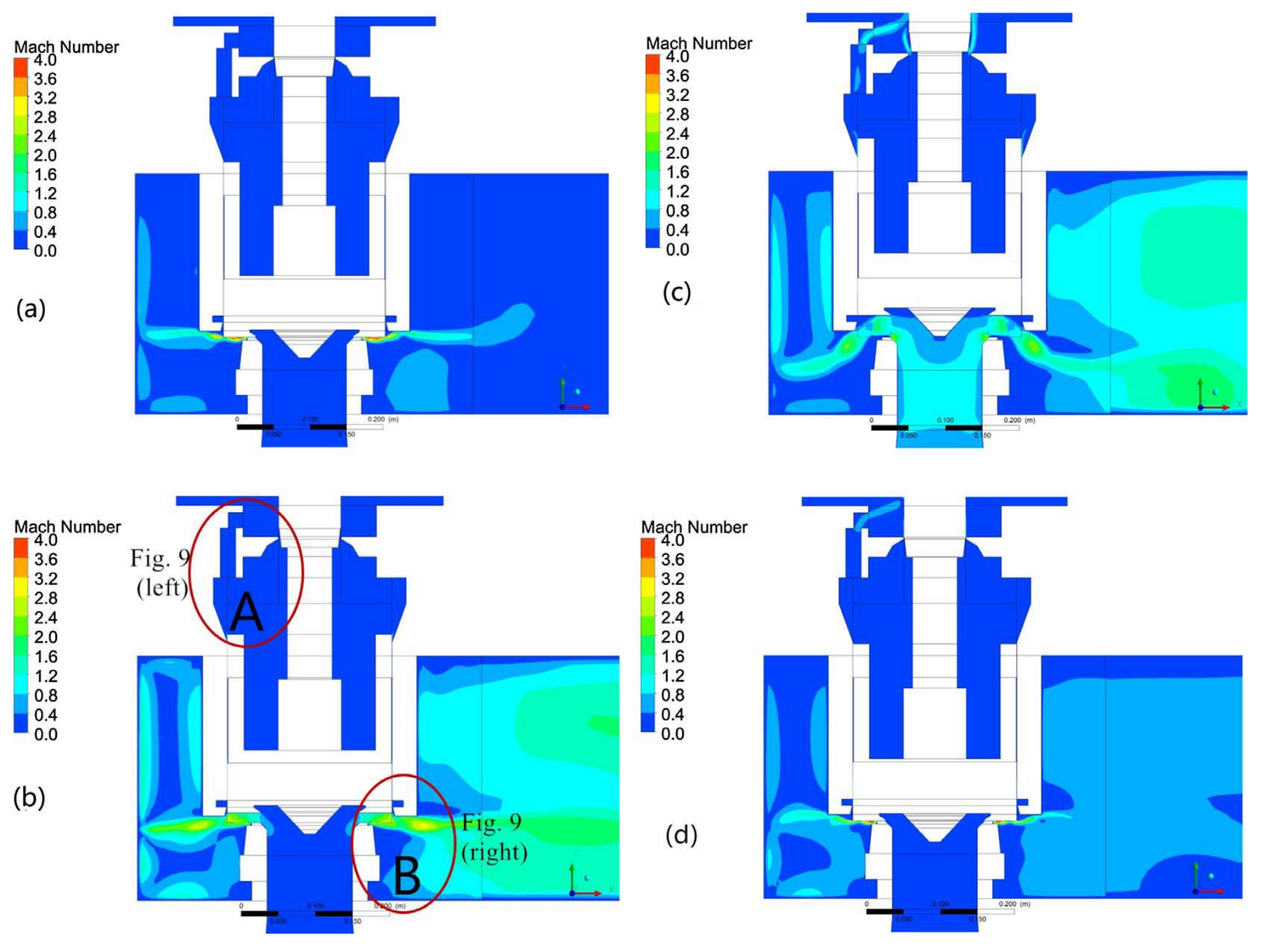

Fig. 8. Mach number contours on the symmetrical plane $\left(k_{\text {spring }}=2027.8 \mathrm{~N} \mathrm{~mm}^{-1}\right.$; throat size of $115 \mathrm{~mm}$ in diameter; $U, L, W$, and $E$ are 9, 3.75, 43.5 and $53 \mathrm{~mm}$, respectively; dry saturated steam). The enlarged views of zones A and B are demonstrated in Fig. 9. 

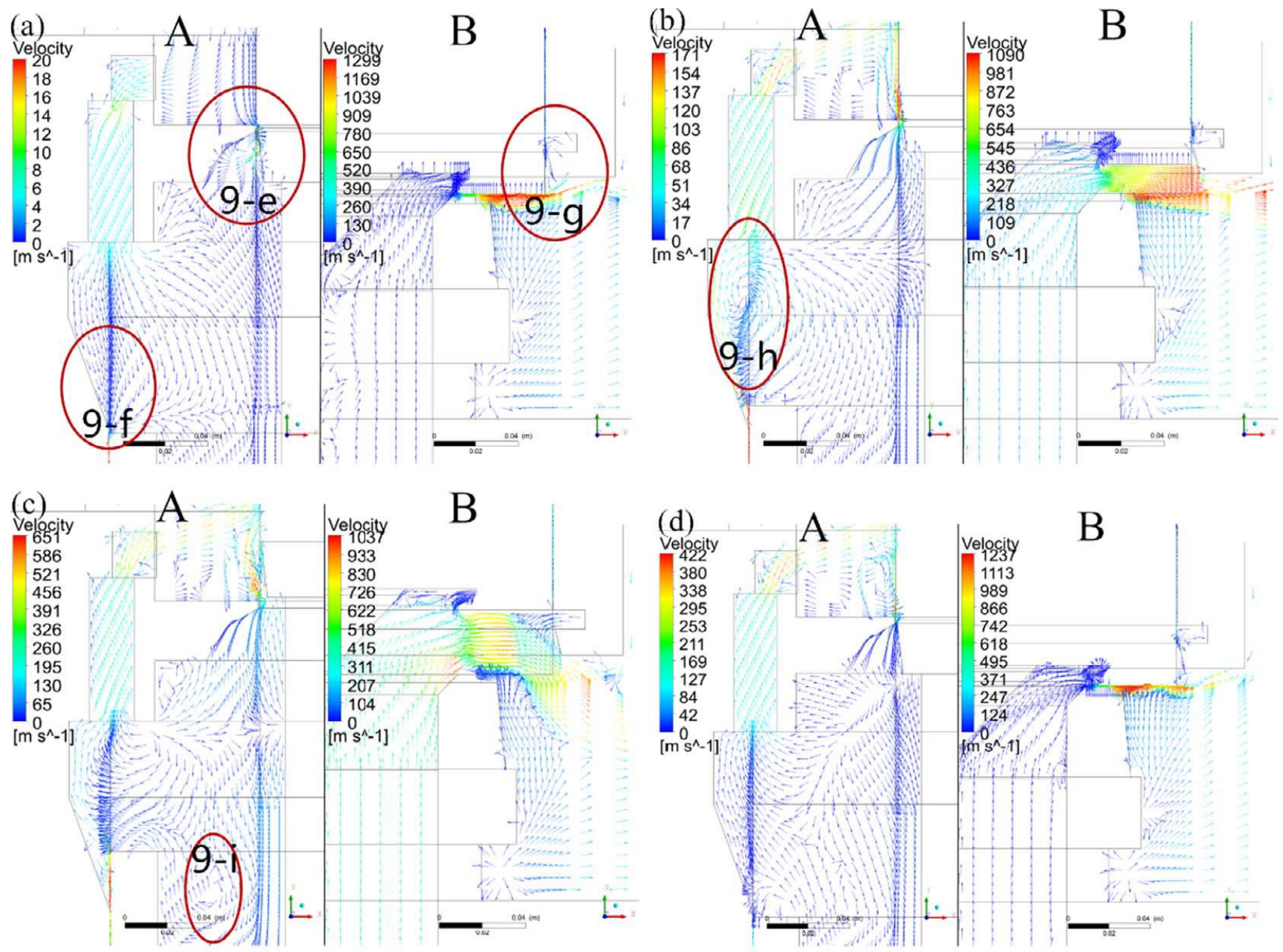

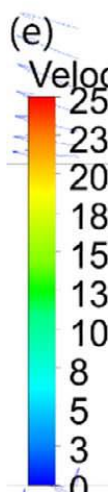

[m $\left.s^{\wedge}-1\right]$ (f)

Velocity
95
86
76
67
57
48
38
29
19
10
0
$\left[\mathrm{~m} \mathrm{~s}^{\wedge}-1\right]$
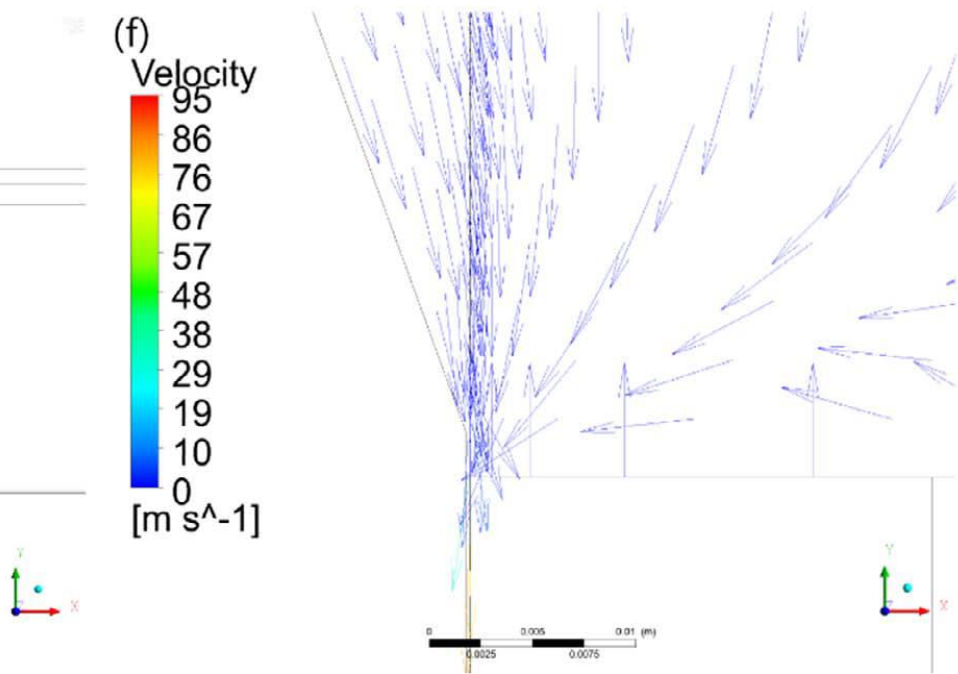

Fig. 9. Velocity vector in the back pressure chamber (left) and open gap (right). $\left(k_{\text {spring }}=2027.8 \mathrm{~N} \mathrm{~mm}^{-1}\right.$; throat size of $115 \mathrm{~mm}$ in diameter; $U, L, W$, and $E$ are $9,3.75,43.5$ and $53 \mathrm{~mm}$, respectively; dry saturated steam). The locations of A and B can be found in Fig. 8. 

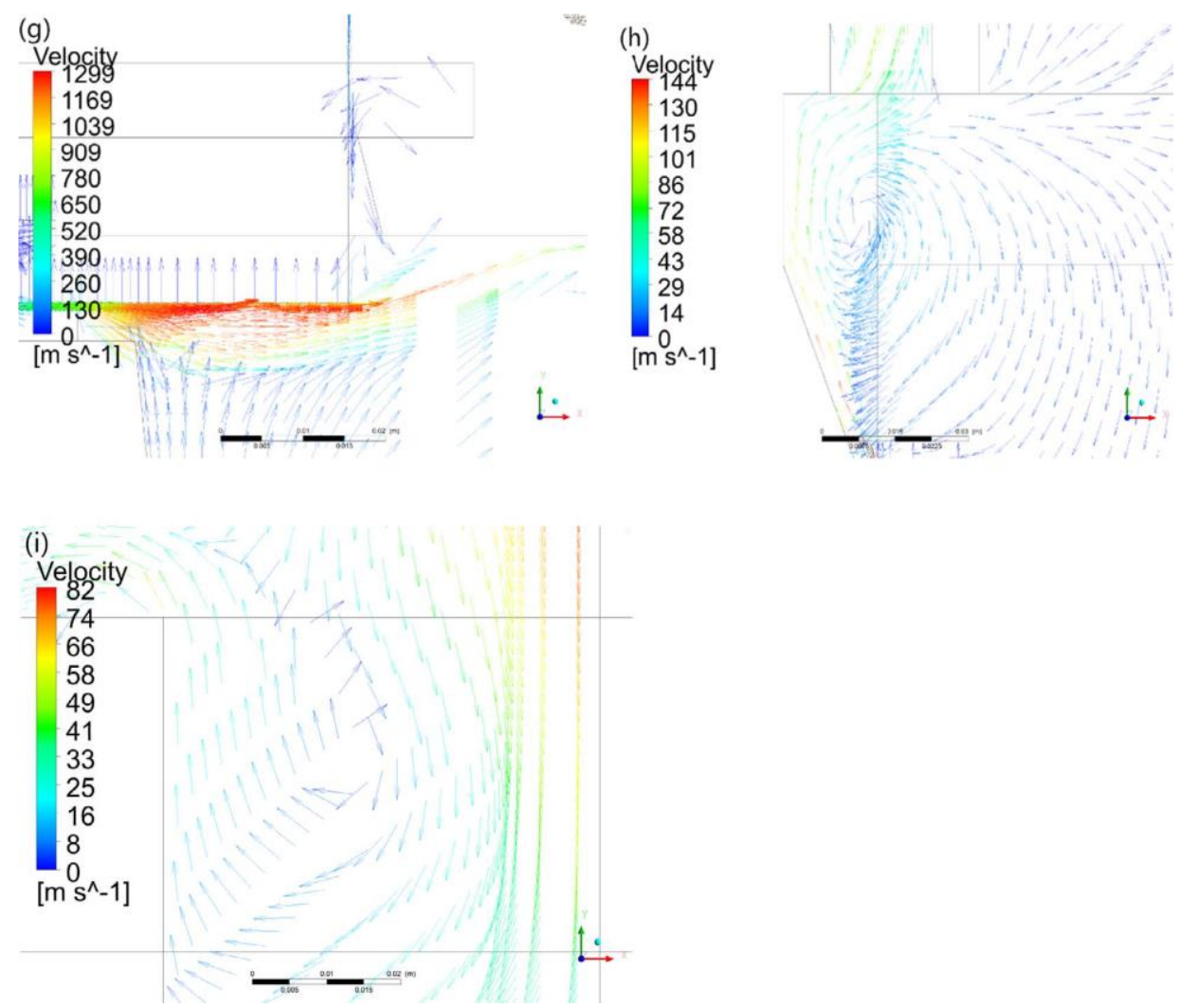

Fig. 9. (continued)

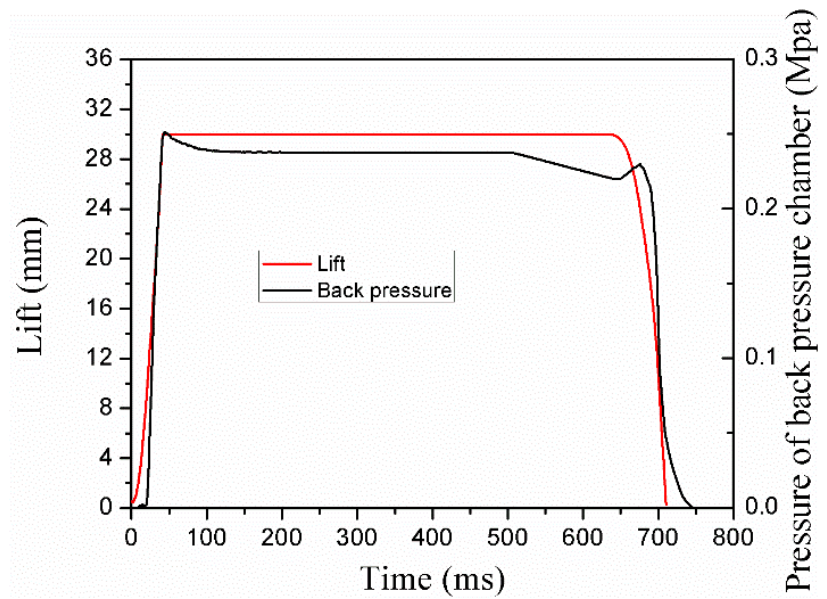

Fig. 10. The relationship between lift and pressure of back chamber. $\left(k_{\text {spring }}=2027.8 \mathrm{~N} \mathrm{~mm}^{-1}\right.$; throat size of $115 \mathrm{~mm}$ in diameter; $U$, $L, W$, and $E$ are $9,3.75,43.5$ and $53 \mathrm{~mm}$, respectively; dry saturated steam). 

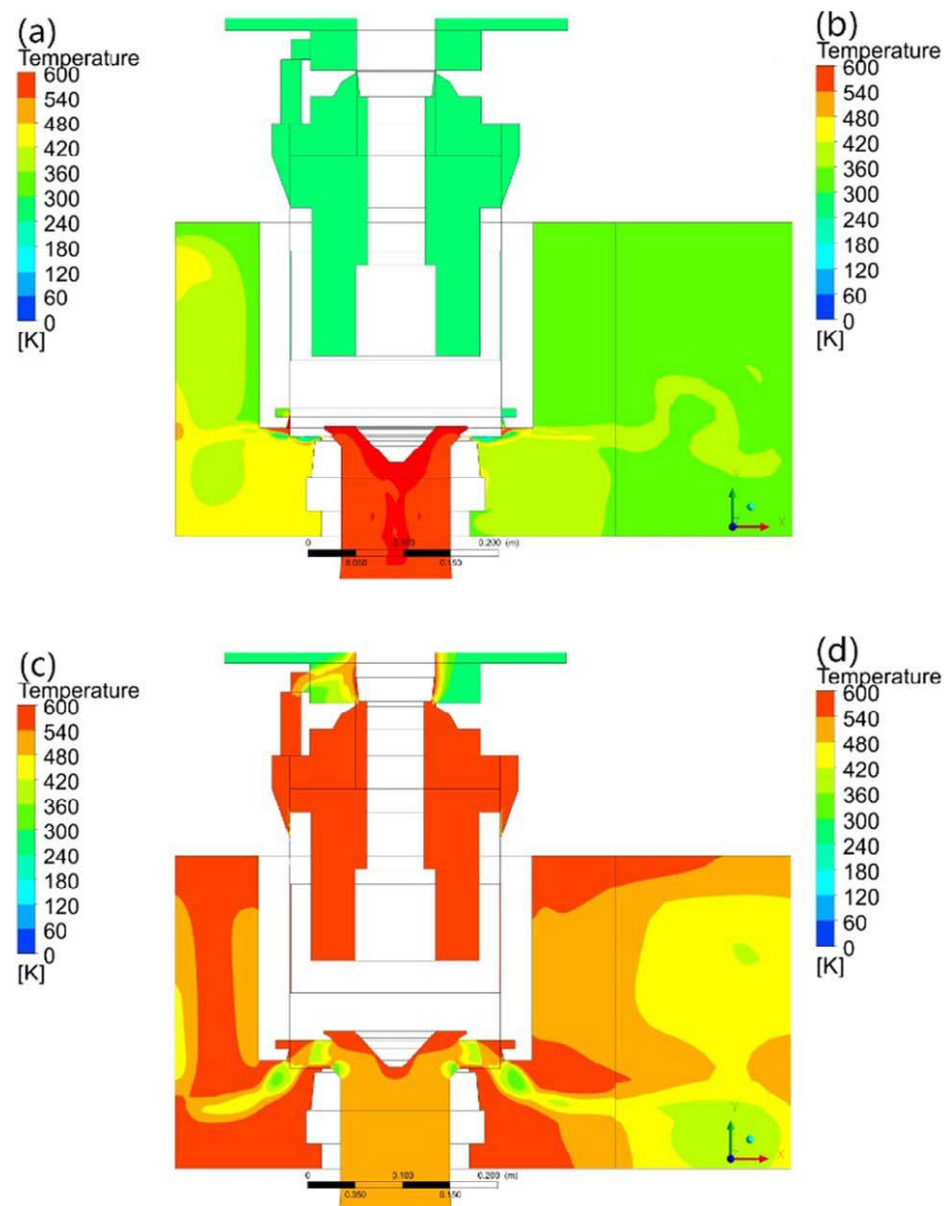
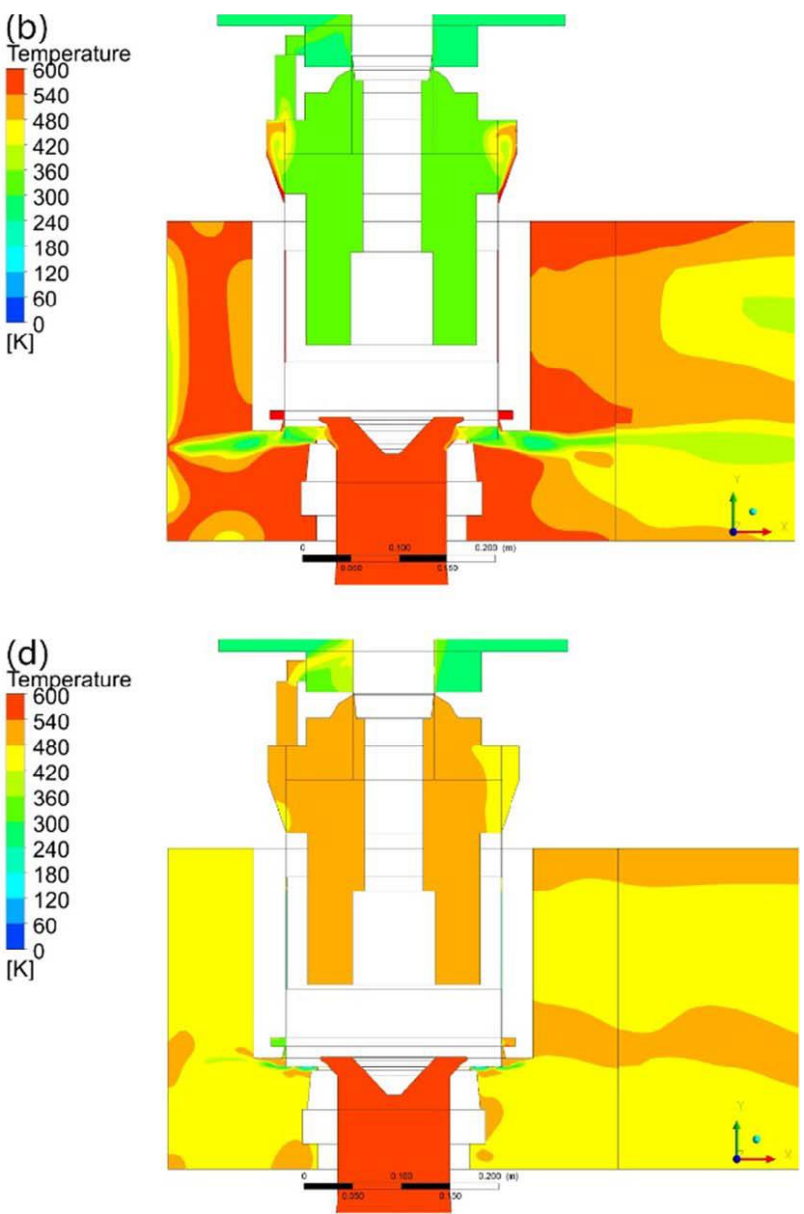

Fig. 11. Temperature contours on the symmetrical plane $\left(\mathrm{k}_{\mathrm{spring}}=2027.8 \mathrm{Nmm}^{-1}\right.$; throat size of $115 \mathrm{~mm}$ in diameter; $\mathrm{U}, \mathrm{L}, \mathrm{W}$, and $\mathrm{E}$ are $9,3.75,43.5$ and $53 \mathrm{~mm}$, respectively; dry saturated steam).

\subsection{Effect of adjusting sleeve}

The effect of the sleeve position $\mathrm{E}$ on the reseating pressure was investigated by varying the sleeve position in the range of 35$71 \mathrm{~mm}$. The values of $\mathrm{W}, \mathrm{U}$, and $\mathrm{L}$ are kept constant at $43.5 \mathrm{~mm}, 9 \mathrm{~mm}$, and $3.75 \mathrm{~mm}$, respectively. The pressure in the test vessel was set to be 7.2 MPa. The pressure at the inlet of the test vessel was $7.416 \mathrm{MPa}$ (relieving pressure, 1.03 times $7.2 \mathrm{MPa}$ ) to guarantee that the disk lifts and reaches the rated value of $30 \mathrm{~mm}$ in all the cases. The simulation results are illustrated in Figs. $12-14$. No effect of $E$ on the pop-up process can be found. The blowdown is in proportion to $E$, when $E$ is in the range of 35-62 $\mathrm{mm}$; the blowdown increases linearly by $0.163 \%$ per $\mathrm{mm}$ increase in E. The pressure in the backpressure chamber increases with the decrease in $\mathrm{E}$, because this adjustment reduces the effective flow area and the steam discharging from the backpressure chamber, thus increasing the pressure of the accumulated steam in the backpressure chamber. Accordingly, the force acting on the 
disk holder increases (Fig. 14). This accelerates the reseating of the PRV, resulting in a high reseating pressure and hence lowering blowdown values.
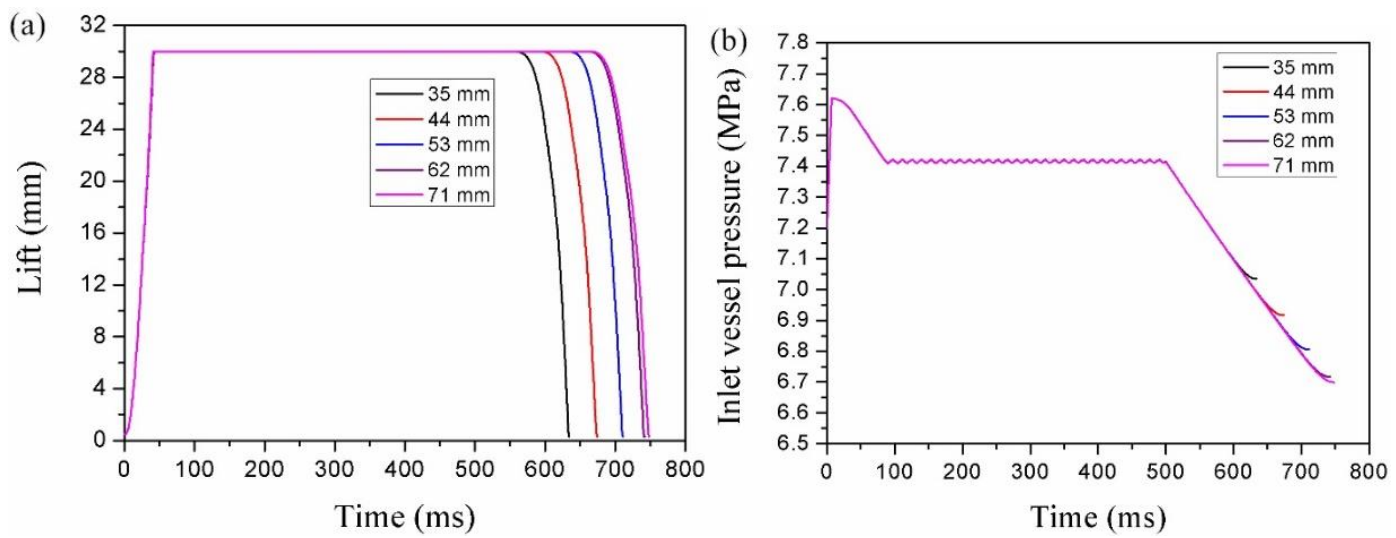

Fig. 12. Lift change (a) and test vessel pressure (b) from open to re-closing of different adjusting sleeve position.

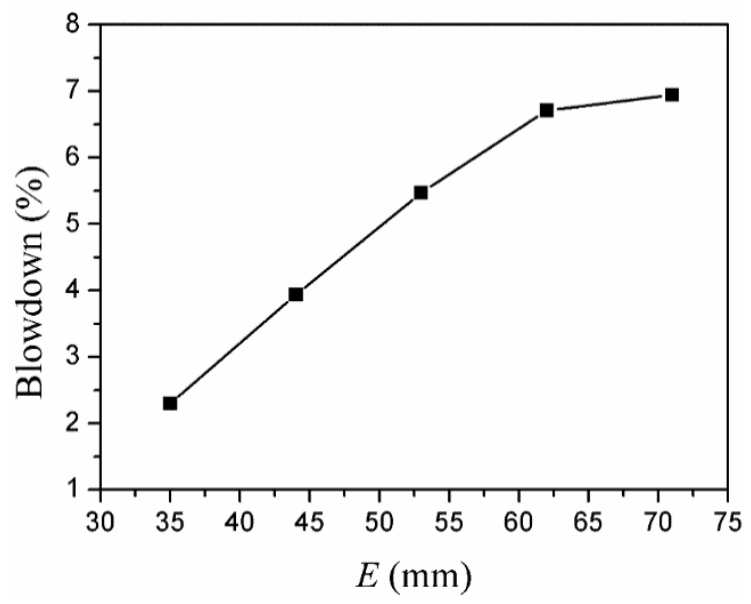

Fig. 13. Blowdown (\%) as a function of $E$.

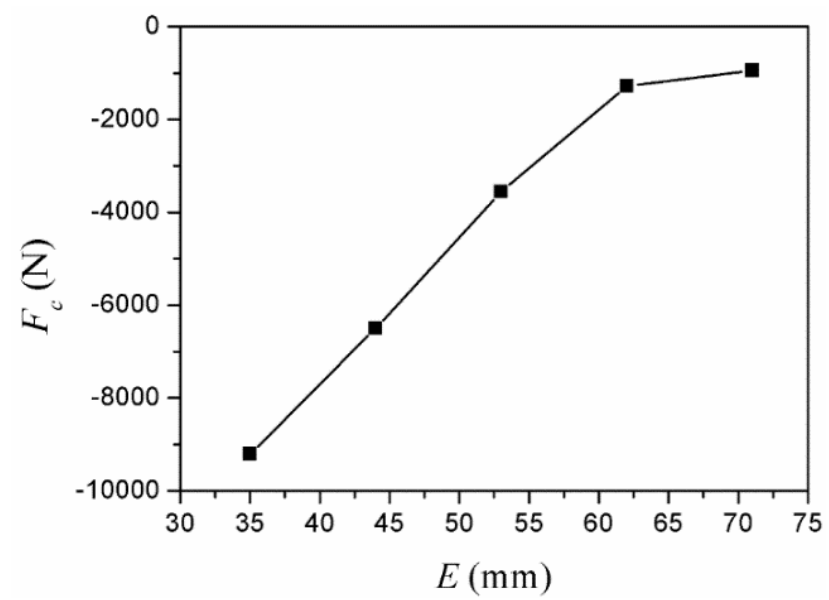

Fig. 14. $F_{c}$ (Force on moving parts (see Eq. (2)) imposed by accumulated steam in back pressure chamber) change with different adjusting sleeve positions $(\mathrm{t}=200 \mathrm{~ms})$. 


\subsection{Response surface methodology model}

To obtain the response (blowdown) under various conditions, simulations were performed in accordance with the design matrix generated by the CCD. The values of E, W, U, and L acted as regulators for the reseating pressure, and were adjusted at the required level for each design configuration, while the other operational parameters of the PRV were kept constant. The actual levels of the variables for each numerical run in the design matrix are presented in Table 1 . The blowdown response predicted by CFD based numerical simulation for each run is presented in Table 2. From the numerical results presented in Table 2 and based on Eq.(6), the second-order response function representing the blowdown could be expressed as a function of the four regulators' positions. Using the quadratic polynomial model, the relationship between the response and variable was obtained in terms of actual units as follows.

$$
\begin{aligned}
\text { Blowdown }(\%)= & -16.20891+0.55624 E+0.38060 W-0.58382 U+0.28553 L-4.01925 \times 10^{-3} E W \\
& +4.62755 \times 10^{-3} E U+7.16111 \times 10^{-4} E L-5.25595 \times 10^{-4} W U+7.64286 \times 10^{-4} W L \\
& -0.019235 U L-2.60732 \times 10^{-3} E^{2}-1.40757 \times 10^{-3} W^{2}-0.030164 U^{2}-6.79533 \times 10^{-3} L^{2}
\end{aligned}
$$

It is an important part of the data analysis to check the adequacy of the model, because the response function could give an inaccurate prediction for some data points. Hence, to assess the significance and capability of the model, an ANOVA analysis was performed, and the results are presented in Table 3. The first column represents the model, main effects (E, W, $\mathrm{U}$, and L), and two-way interaction effects (EW-L2). The second column shows the sum of squares (SS) used to measure the variability in the data. The third column represents the degree of freedom (df). The fourth column shows the mean square (MS), which is equivalent to SS divided by df. The fifth column shows the F-value, and the sixth column shows the p-value. The adequate precision ratio measures the signal to noise ratio, and R2 indicates the coefficient of multiple determination. A large value of the coefficient of multiple determination, e.g., $\mathrm{R} 2=0.9951$, indicates that $99.51 \%$ of the variance in the response can be explained by the quadratic model. A large F-value, e.g., 216.48, implies good significance of the regression model. Similarly, p-values less than 0.05 indicate that the model terms are statistically significant, and p-values greater than 0.1 indicate that the model terms are insignificant. For adequate precision, a ratio greater than 4 is desirable. A precision ratio of 57.233 obtained in the present case suggests an adequate signal. The observed (CFD numerical) results and the predicted values obtained using the model equation for blowdown are shown in Fig. 15. It can be observed that there is adequate agreement between the data obtained through simulation and the predicted ones, indicating that the developed regression quadratic models can be used to calculate accurately the response factors for any given variable in the interval range of the numerical design. This agreement is also confirmed by the AP value (AP $>4)$ for the blowdown response. This verifies that the predicted model can be used to navigate the design space defined by the CCD procedure. 
Table 2 Simulation design layout and simulation results of the responses.

\begin{tabular}{|c|c|c|c|c|c|c|}
\hline \multirow[t]{2}{*}{ Run } & \multicolumn{4}{|c|}{ Actual and coded levels of variables } & \multicolumn{2}{|c|}{ Blowdown (\%) } \\
\hline & $E(\mathrm{~mm})$ & $W(\mathrm{~mm})$ & $\mathrm{U}(\mathrm{mm})$ & $\mathrm{L}(\mathrm{mm})$ & $\begin{array}{c}\text { CFD } \\
\text { Numerical value }\end{array}$ & $\begin{array}{c}\text { Predicted } \\
\text { value }\end{array}$ \\
\hline 1 & $44(-1)$ & $40(-1)$ & $6(-1)$ & $2.5(-1)$ & 5.91 & 6.16 \\
\hline 2 & $62(1)$ & $40(-1)$ & $6(-1)$ & $2.5(-1)$ & 8.74 & 8.84 \\
\hline 3 & $44(-1)$ & $47(1)$ & $6(-1)$ & $2.5(-1)$ & 6.49 & 6.72 \\
\hline 4 & $62(1)$ & $47(1)$ & $6(-1)$ & $2.5(-1)$ & 8.83 & 8.89 \\
\hline 5 & $44(-1)$ & $40(-1)$ & $12(1)$ & $2.5(-1)$ & 0.18 & 0.21 \\
\hline 6 & $62(1)$ & $40(-1)$ & $12(1)$ & $2.5(-1)$ & 3.56 & 3.38 \\
\hline 7 & $44(-1)$ & $47(1)$ & $12(1)$ & $2.5(-1)$ & 0.77 & 0.75 \\
\hline 8 & $62(1)$ & $47(1)$ & $12(1)$ & $2.5(-1)$ & 3.63 & 3.41 \\
\hline 9 & $44(-1)$ & $40(-1)$ & $6(-1)$ & $5(1)$ & 6.41 & 6.61 \\
\hline 10 & $62(1)$ & $40(-1)$ & $6(-1)$ & $5(1)$ & 9.29 & 9.32 \\
\hline 11 & $44(-1)$ & $47(1)$ & $6(-1)$ & $5(1)$ & 7.01 & 7.19 \\
\hline 12 & $62(1)$ & $47(1)$ & $6(-1)$ & $5(1)$ & 9.43 & 9.39 \\
\hline 13 & $44(-1)$ & $40(-1)$ & $12(1)$ & $5(1)$ & 0.43 & 0.37 \\
\hline 14 & $62(1)$ & $40(-1)$ & $12(1)$ & $5(1)$ & 3.82 & 3.58 \\
\hline 15 & $44(-1)$ & $47(1)$ & $12(1)$ & $5(1)$ & 1.02 & 0.92 \\
\hline 16 & $62(1)$ & $47(1)$ & $12(1)$ & $5(1)$ & 3.87 & 3.62 \\
\hline 17 & $35(-2)$ & $43.5(0)$ & $9(0)$ & $3.75(0)$ & 2.30 & 1.94 \\
\hline 18 & $71(2)$ & $43.5(0)$ & $9(0)$ & $3.75(0)$ & 6.95 & 7.31 \\
\hline 19 & $53(0)$ & $36.5(-2)$ & $9(0)$ & $3.75(0)$ & 5.17 & 5.10 \\
\hline 20 & $53(0)$ & $50.5(2)$ & $9(0)$ & $3.75(0)$ & 5.63 & 5.70 \\
\hline 21 & $53(0)$ & $43.5(0)$ & $3(-2)$ & $3.75(0)$ & 10.75 & 10.24 \\
\hline 22 & $53(0)$ & $43.5(0)$ & $15(2)$ & $3.75(0)$ & -1.99 & $-1.47^{\mathrm{a}}$ \\
\hline 23 & $53(0)$ & $43.5(0)$ & $9(0)$ & $1.25(-2)$ & 5.22 & 5.10 \\
\hline 24 & $53(0)$ & $43.5(0)$ & $9(0)$ & $6.25(2)$ & 5.63 & 5.76 \\
\hline 25 & $53(0)$ & $43.5(0)$ & $9(0)$ & $3.75(0)$ & 5.47 & 5.47 \\
\hline 26 & $53(0)$ & $43.5(0)$ & $9(0)$ & $3.75(0)$ & 5.47 & 5.47 \\
\hline 27 & $53(0)$ & $43.5(0)$ & $9(0)$ & $3.75(0)$ & 5.47 & 5.47 \\
\hline 28 & $53(0)$ & $43.5(0)$ & $9(0)$ & $3.75(0)$ & 5.47 & 5.47 \\
\hline 29 & $53(0)$ & $43.5(0)$ & $9(0)$ & $3.75(0)$ & 5.47 & 5.47 \\
\hline 30 & $53(0)$ & $43.5(0)$ & $9(0)$ & $3.75(0)$ & 5.47 & 5.47 \\
\hline
\end{tabular}

${ }^{\mathrm{a}}$ Chattering occurs in this case and the value is the first reseating value.

\subsection{Effects of factors on blowdown using response surfaces}

By mapping the response surface over the closed regions, the effects of various factors on the responses could be analyzed. Three-dimensional response surface plots of the predictive quadratic model for the effects of the four factors on blowdown are presented. The response surfaces were generated based on Eq. (11). Fig. 16(a) shows the response surface for blowdown 
against $\mathrm{E}$ and $\mathrm{W}$, when $\mathrm{U}$ and $\mathrm{L}$ are kept at constant values of 9 and $3.75 \mathrm{~mm}$, respectively. The blowdown increases with an increase in $\mathrm{E}$. The increase in $\mathrm{W}$ has a negligible effect on blowdown. The effects of varying $\mathrm{E}$ and $\mathrm{U}$ on blowdown are shown in Fig. 16(b). The blowdown increases with a decrease in U, and depends more on $U$ than on E. The decrease in U causes a more significant increase in blowdown for the case of a higher E value.

Table 3 Analysis of variance for RSM model.

\begin{tabular}{|c|c|c|c|c|c|c|}
\hline Source & $\begin{array}{c}\text { Sum of } \\
\text { squares }\end{array}$ & $d f$ & Mean square & F value & $\begin{array}{c}\text { P value } \\
\text { Prob }>\text { F }\end{array}$ & $\begin{array}{c}\text { Model } \\
\text { performance }\end{array}$ \\
\hline Model & 254.11 & 14 & 18.15 & 216.48 & $<0.0001$ & significant \\
\hline$E$ & 43.37 & 1 & 43.37 & 517.25 & $<0.0001$ & significant \\
\hline$W$ & 0.55 & 1 & 0.55 & 6.56 & 0.0217 & significant \\
\hline$U$ & 205.97 & 1 & 205.97 & 2456.68 & $<0.0001$ & significant \\
\hline$L$ & 0.66 & 1 & 0.66 & 7.87 & 0.0133 & significant \\
\hline$E W$ & 0.26 & 1 & 0.26 & 3.06 & 0.1007 & insignificant \\
\hline$E U$ & 0.25 & 1 & 0.25 & 2.98 & 0.1049 & insignificant \\
\hline$E L$ & $1.038 \mathrm{E}-003$ & 1 & $1.038 \mathrm{E}-003$ & 0.012 & 0.9129 & insignificant \\
\hline$W U$ & $4.873 \mathrm{E}-004$ & 1 & $4.873 \mathrm{E}-004$ & $5.812 \mathrm{E}-003$ & 0.9402 & insignificant \\
\hline$W L$ & $1.789 \mathrm{E}-004$ & 1 & $1.789 \mathrm{E}-004$ & $2.134 \mathrm{E}-003$ & 0.9638 & insignificant \\
\hline$U L$ & 0.083 & 1 & 0.083 & 0.99 & 0.3348 & insignificant \\
\hline$E^{2}$ & 1.22 & 1 & 1.22 & 14.59 & 0.0017 & significant \\
\hline$W^{2}$ & $8.155 \mathrm{E}-003$ & 1 & $8.155 \mathrm{E}-003$ & 0.097 & 0.7594 & insignificant \\
\hline$U^{2}$ & 2.02 & 1 & 2.02 & 24.11 & 0.0002 & significant \\
\hline$L^{2}$ & $3.092 \mathrm{E}-003$ & 1 & $3.092 \mathrm{E}-003$ & 0.037 & 0.8503 & insignificant \\
\hline Residual & 1.26 & 15 & 0.084 & & & \\
\hline Lack of fit & 1.26 & 10 & 0.13 & & & \\
\hline Pure error & 0.000 & 5 & 0.000 & & & \\
\hline Cor total & 255.37 & 29 & & & & \\
\hline
\end{tabular}

Adequate precision $(\mathrm{AP})=57.233$

$R^{2}=0.9951, R^{2}$ (predicted) $=0.9716, R^{2}$ (adjusted) $=0.9905$.

The effects of various pairs of factors (i.e., $\mathrm{E}$ and L, $\mathrm{U}$ and $\mathrm{W}$, as well as $\mathrm{U}$ and $\mathrm{L}$ ) show the same tendency; one factor plays a more important role than the other. E and U contribute more to the change in blowdown, as illustrated in Fig. 16(c), (d), and (f). It can be observed that the increases in both W and L slightly increase the blowdown (see Fig. 16(e)). As shown in Fig. 16(a)-(c), the blowdown increases with an increase in E. This is because the increase in the distance between points A and $\mathrm{B}$ causes a decrease in the force imposed by the accumulated steam in the backpressure chamber, as mentioned in Section 5.3 and shown in Fig. 14. From Fig. 16(a), (d), and (e), it can be seen that an increase in W exhibits a positive but negligible effect on the blowdown. This is because the change in the effective flow area for the steam discharging from the Fig. 16. continued) backpressure chamber is negligible with the change in W. As shown in Fig. 16(b), (d), and (f), the blowdown decreases almost linearly with an increase in $U$, because the upward movement of the upper adjusting ring leads 
to a decrease in the force generated by the flow, thus increasing the downward resultant force imposed on the moving parts during reseating. As in the case of W, L also plays a positive but negligible role in the blowdown (see Fig. 16(c), (e), and (f)). It may be noted that the effects of $\mathrm{E}, \mathrm{W}, \mathrm{U}$, and $\mathrm{L}$ on the discharge flow rates of the PRV are negligible for all the cases considered in this study. As presented in Table 3, E, W, U, L, E2, and U2 are the most significant terms, considering that their p-values are less than 0.05 . An important corollary to the above, as seen from the analysis, is that the cross-coupling terms (EU, EW, etc.) are insignificant, indicating that each parameter is independent of the others. This is an important practical outcome when one has to adjust the valve, as any given setting will not be influenced by the other settings. To improve the model and optimize the results, the insignificant terms can be ignored ( $p$-value $>0.100$ ). After removing the insignificant terms, a new predictive model for the PRV is generated as given below.

$$
\begin{aligned}
\text { Blowdown }(\%)= & -5.67864+0.42118 E+0.043254 W-0.44052 U \\
& +0.13265 L-2.56432 \times 10^{-3} E^{2}-0.029778 U^{2}
\end{aligned}
$$

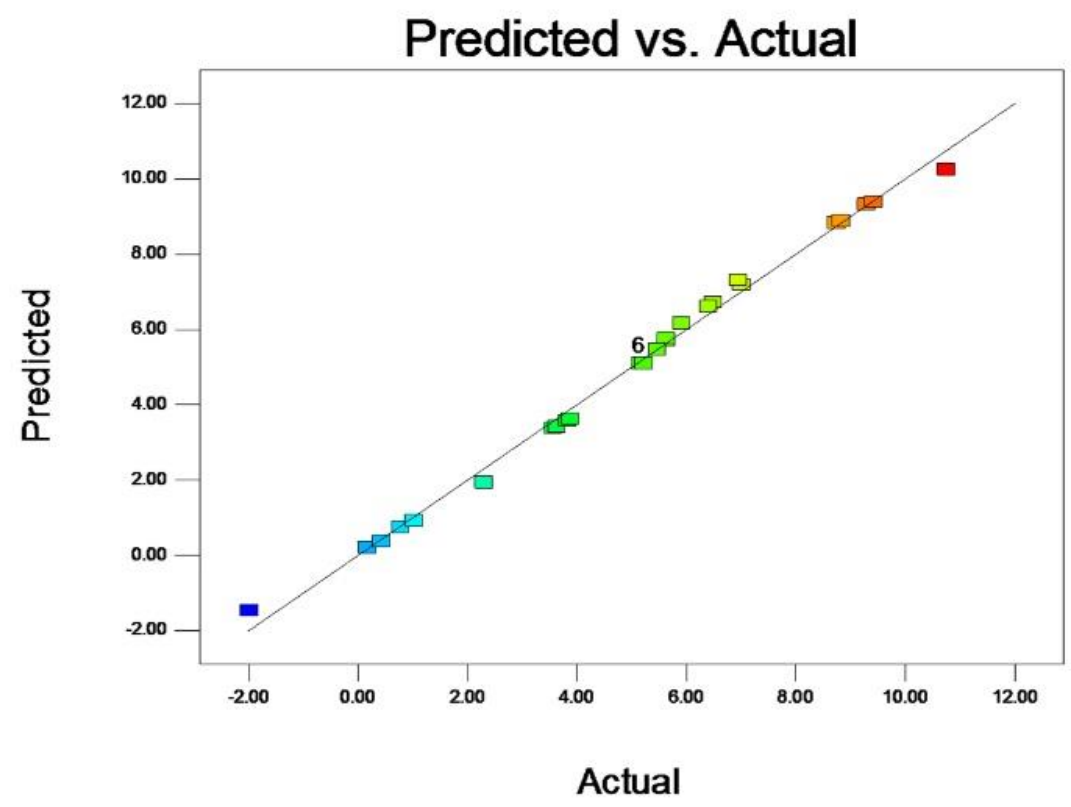

Fig. 15. Design-expert plot: predicted vs. actual values for reseating pressure/setting pressure 
(a)

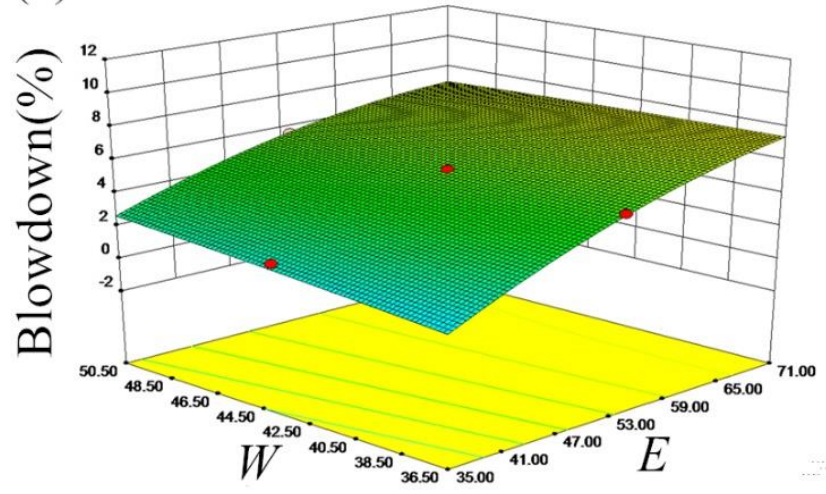

(b)

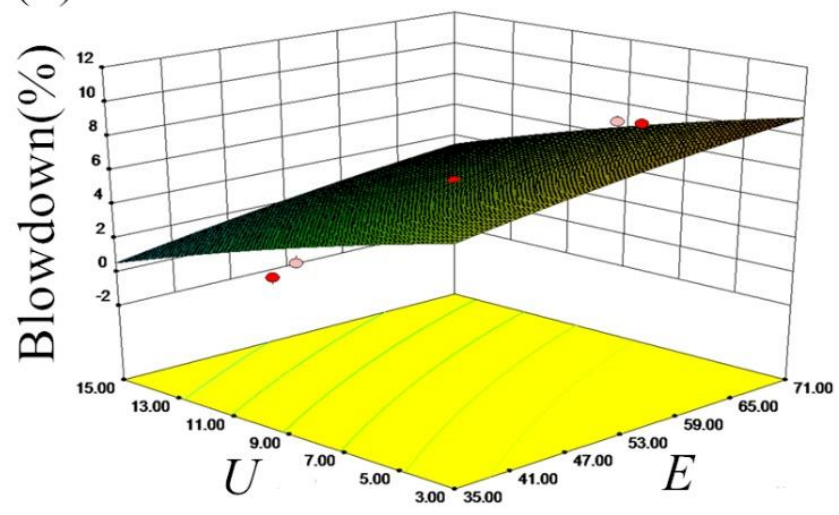

(c)

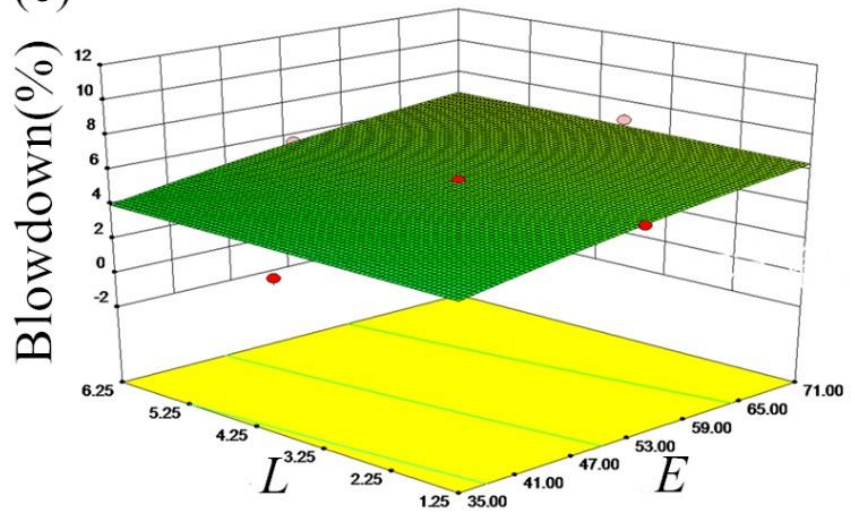

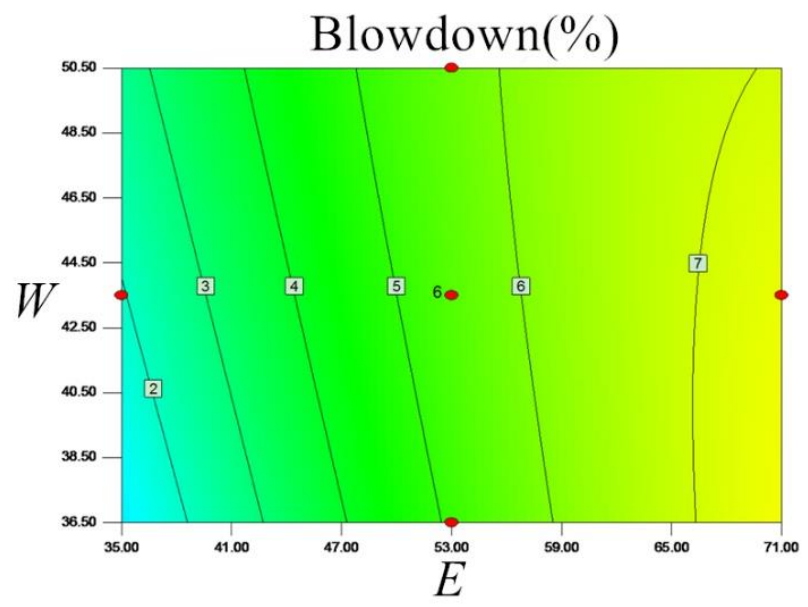
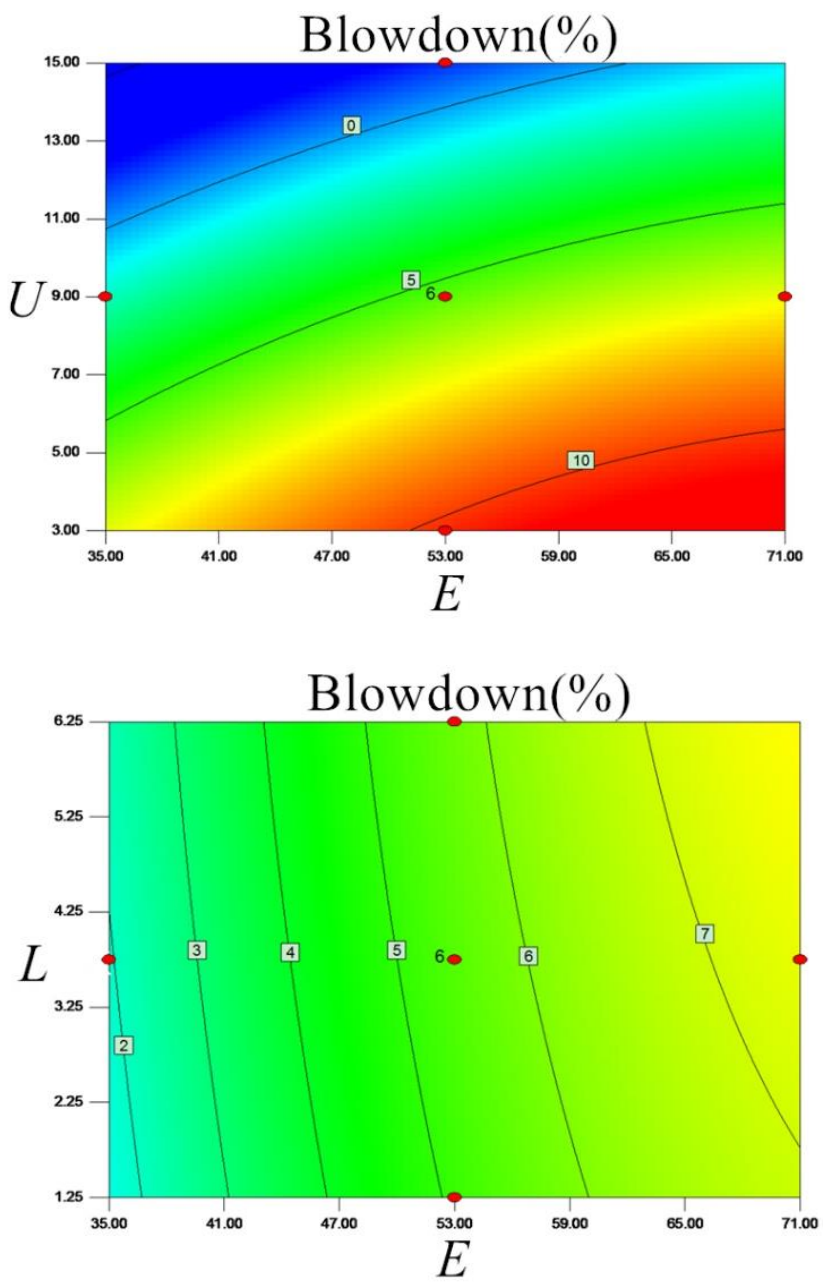

Fig. 16. Response surface plots. (a) influence of $W, E$ and their interaction on blowdown $(U=9, L=3.75)$; (b) influence of $U, E$ and their interaction on blowdown ( $W=43.5, L=3.75)$; (c) influence of $L, E$ and their interaction on blowdown $(W=43.5, U=9)$; (d) influence of $U, W$ and their interaction on blowdown $(E=53, L=3.75)$; (e) influence of $L, W$ and their interaction on blowdown $(E=53, U=9)$; (f) influence of $L, U$ and their interaction on blowdown $(E=53, W=43.5)$. 
(d)

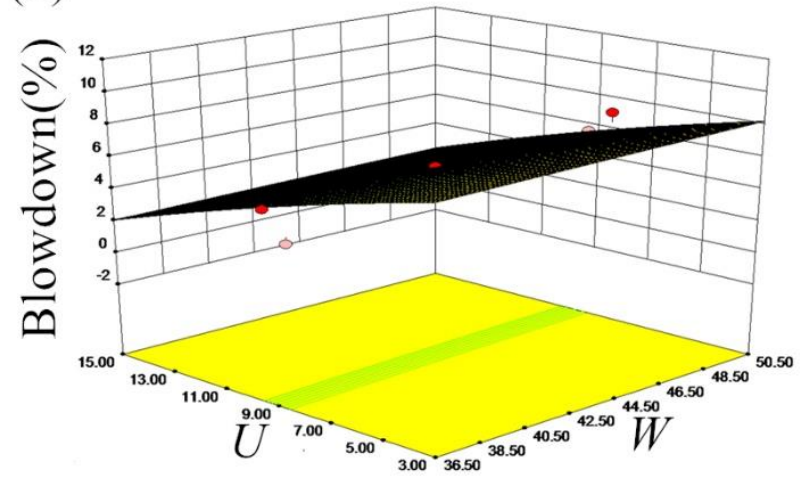

(e)

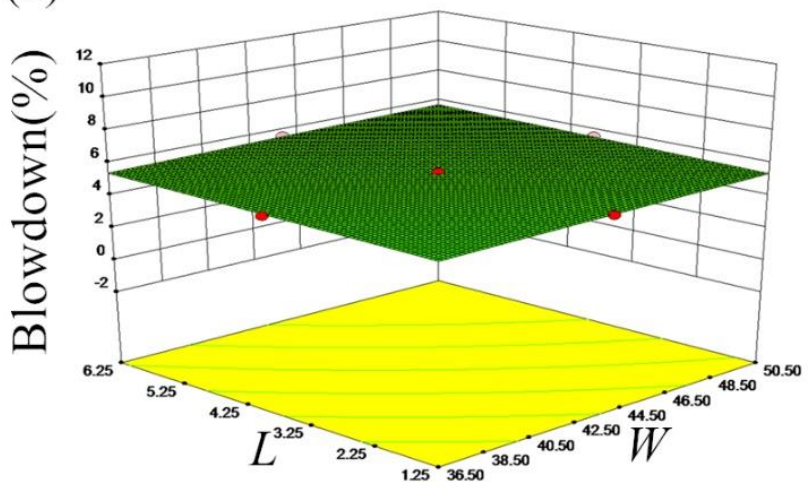

(f)

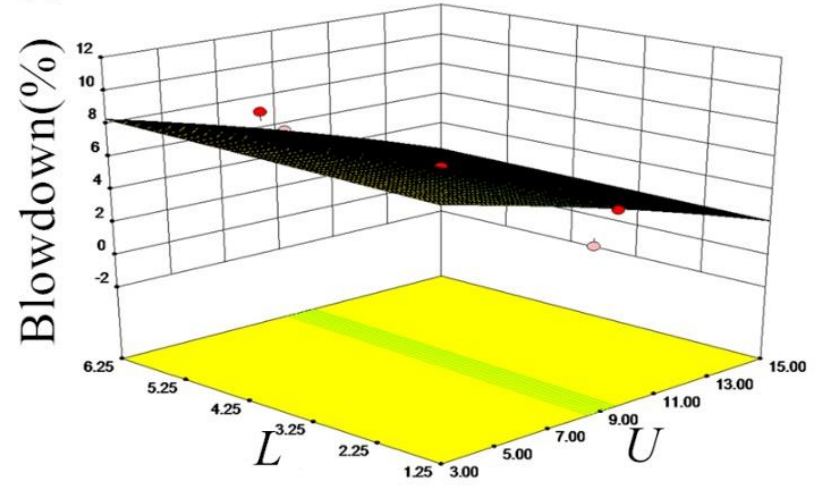

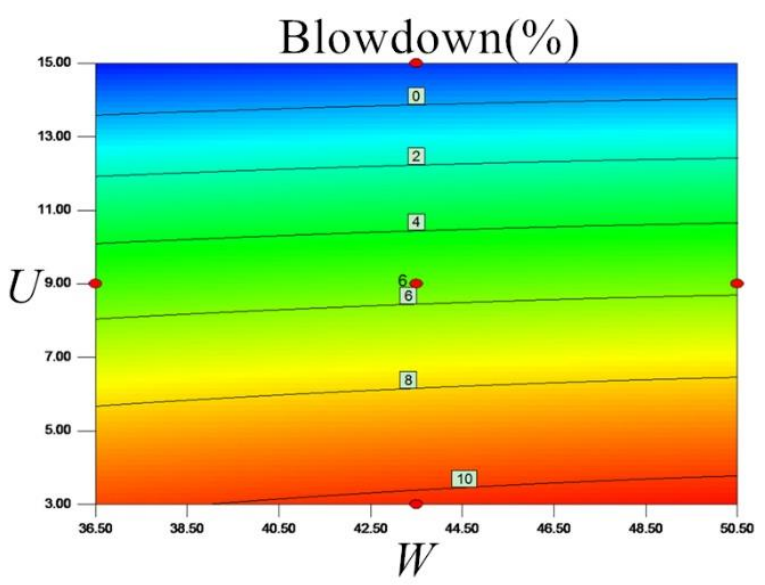
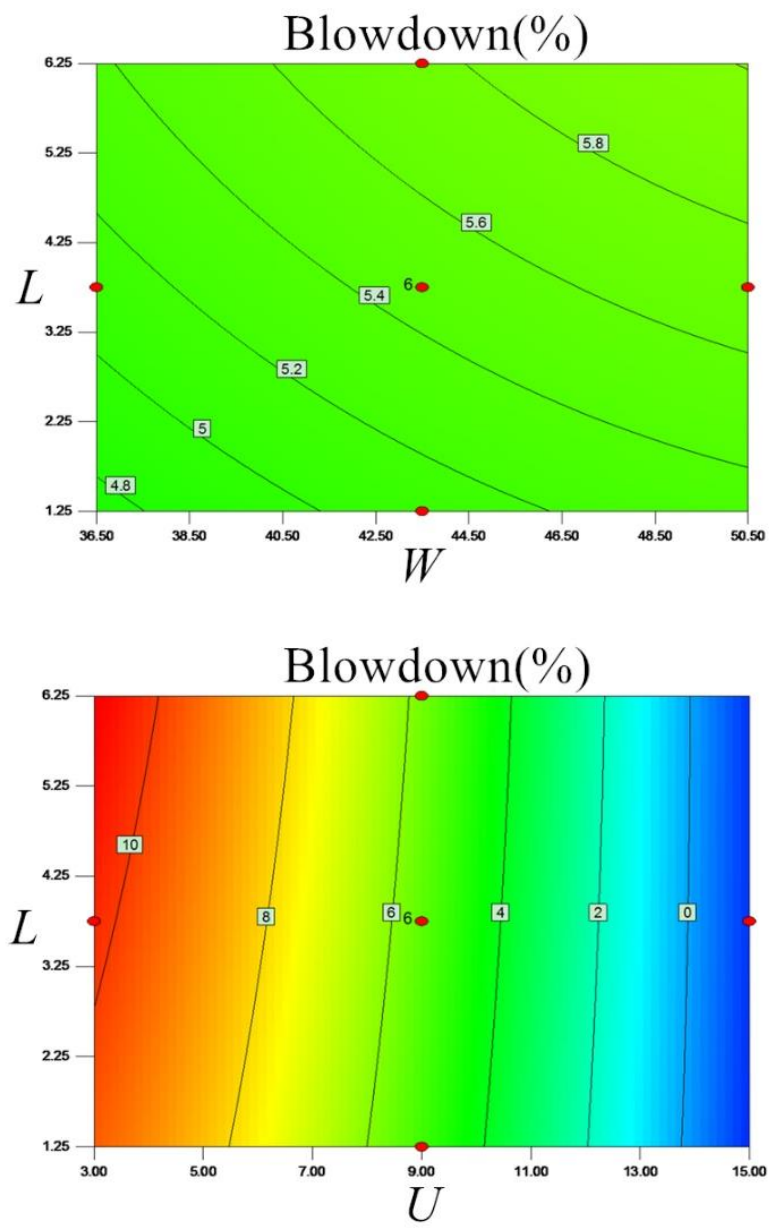

Fig. 16. Response surface plots. Continued (d) influence of $U, W$ and their interaction on blowdown $(E=53, L=3.75)$; (e) influence of $L, W$ and their interaction on blowdown $(E=53, U=9)$; (f) influence of $L, U$ and their interaction on blowdown $(E=53, W=43.5)$. 


\section{Conclusions}

A complex pressure relief valve incorporating upper and lower adjusting rings, and combined with a backpressure chamber, has been studied in an attempt to predict the blowdown behavior and explicitly relate this to the controlling geometrical parameters of the adjusting element positions. The following are the results of the study.

(i) It is possible to model such a complex valve using transient CFD techniques and obtain good prediction results, with a difference of less than $0.6 \%$ in the blowdown values when compared with experimental values.

(ii) The response of the pressure in the backpressure chamber showed that the chamber gas dynamics were coupled with the disk motion; thus, it would be difficult to account for the dynamics by any method other than through modelling. The backpressure chamber assisted the reseating and decreased the blowdown of the NPMS PRV from $18.13 \%$ to $5.50 \%$.

(iii) The complex influence of the geometrical parameters on blowdown can be successfully captured by using a combination of the central composite design technique and response surface approach to create an accurate relationship between the blowdown and the positions of the adjusting elements.

(iv) An important outcome from ANOVA is that the setting parameters are independent of one another; this reduces the complexity of the valve setting operations.

(v) From a practical viewpoint, the response surface approach to PRV analysis could lead to a significant reduction in design and testing efforts by allowing the complex valve adjustment for blowdown to be captured accurately (with a relative error of $1 \%$ ) with a simple algebraic expression.

\section{Acknowledgements}

This study was financially supported by the China Natural Science Foundation (Contract No. 21176069, 21476073) and the Fundamental Research Funds for the Central Universities (WG1213011).

\section{Appendix A. Supplementary material}

Supplementary data associated with this article can be found, Appendix A 


\section{References}

[1] M. Rogovin, Three Mile Island: A report to the commissioners and to the public, Nuclear Regulatory Commission, Washington, DC, USA, 1979.

[2] T. Qiu, H. Dai, Y. Lei, X. Song, C. Cao, M. Lai, Dynamic flow behavior during fuel offloadedprocess in control valve for unit pump fuel system, Appl. Therm. Eng. 106 (2016) 153-160.

[3] W. Dempster, C.K. Lee, J. Deans, Prediction of the flow and force characteristics of safety relief valves, ASME 2006 Pressure Vessels and Piping/ICPVT-11 Conference, American Society of Mechanical Engineers, 2006, pp. 93-99.

[4] H.D. Kim, J.H. Lee, K.A. Park, A study of the gas flow through a LNG safety valve, J. Therm. Sci. 15 (4) (2006) 355-360.

[5] A.J. Ortega, B.N. Azevedo, Pires LFG. A numerical model about the dynamic behaviour of a pressure relief valve, in: 12th Brazilian Congress of Thermal Engineering and Sciences, 2008, pp. 1-8.

[6] J. Schmidt, W. Peschel, A. Beune, Experimental and theoretical studies on high pressure safety valves: sizing and design supported by numerical calculations (CFD), Chem. Eng. Technol. 32 (2) (2009) 252-262.

[7] D. Moncalvo, L. Friedel, B. Jörgensen, T. Höhne, Sizing of safety valves using ANSYS CFX-Flo®, Chem. Eng. Technol. 32 (2) (2009) 247-251.

[8] A. Beune, J.G.M. Kuerten, M.P.C. van Heumen, CFD analysis with fluid-structure interaction of opening high-pressure safety valves, Comput. Fluids 64 (2012) 108-116.

[9] F. Bassi, F. Cecchi, N. Franchina, S. Rebay, M. Savini, High-order discontinuous Galerkin computation of axisymmetric transonic flows in safety relief valves, Comput. Fluids 49 (1) (2011) 203-213.

[10] V. Dossena, F. Marinoni, F. Bassi, N. Franchina, M. Savini, Numerical and experimental investigation on the performance of safety valves operating with different gases, Int. J. Pressure Vessels Piping 104 (4) (2013) 21-29.

[11] W. Dempster, W. Elmayyah, Two phase discharge flow prediction in safety valves, Int. J. Pressure Vessels Piping 110 (10) (2013) 61-65.

[12] M. Alshaikh, W. Dempster, A CFD study of two-phase frozen flow of air/water through a safety relief valve, Int. J. Chem. Reactor Eng. 13 (4) (2015) 533-540.

[13] R. Darby, The dynamic response of pressure relief valves in vapor or gas service, part I: Mathematical model, J. Loss Prevent. Process Ind. 26 (6) (2013) 1262-1268.

[14] R. Darby, A.A. Aldeeb, The dynamic response of pressure relief valves in vapor or gas service. Part III: Model validation, J. Loss Prevent. Process Ind. 31 (6) (2014) 133-141.

[15] C.J. Hös, A.R. Champneys, K. Paul, M. McNeely, Dynamic behavior of direct spring loaded pressure relief valves in gas service: model development, measurements and instability mechanisms, J. Loss Prevent. Process Ind. 31 (1) (2014) 70-81.

[16] X.G. Song, L. Wang, Y.C. Park, Transient analysis of a spring-loaded pressure safety valve using computational fluid dynamics (CFD), J. Pressure Vessel Technol. 132 (2010) 1-5.

[17] X.G. Song, Y.C. Park, J.H. Park, Blowdown prediction of a conventional pressure relief valve with a simplified dynamic model, Math. Comput. Modell. 57 (1) (2013) 279-288. 
[18] X.G. Song, L. Cui, M.S. Cao, W.P. Cao, Y.C. Park, W. Dempster, A CFD analysis of the dynamics of a direct-operated safety relief valve mounted on a pressure vessel, Energy Convers. Manage. 81 (2014) 407-419.

[19] X.G. Song, L. Wang, S.H. Baek, Y.C. Park, Multidisciplinary optimization of a butterfly valve, Isa Trans. 48 (3) (2009) 370377.

[20] L. Yang, Z. Wang, W. Dempster, X.H. Yu, S.T. Tu, Experiments and transient simulation on spring-loaded pressure relief valve under high temperature and high pressure steam conditions, J. Loss Prevent. Process Ind. 45 (2017) 133-146.

[21] ASME PTC 25-2001, Pressure Relief Devices Performance Test Code.

[22] K.T. Chiang, Modeling and optimization of designing parameters for a parallel-plain fin heat sink with confined impinging jet using the response surface methodology, Appl. Therm. Eng. 27 (14-15) (2007) 2473-2482.

[23] M.Y. Can, Y. Kaya, O.F. Algur, Response surface optimization of the removal of nickel from aqueous solution by cone biomass of Pinus sylvestris, Biores. Technol. 97 (14) (2006) 1761-1765.

[24] B.K. Körbahti, M.A. Rauf, Response surface methodology (RSM) analysis of photo induced decoloration of toludine blue, Chem. Eng. J. 136 (1) (2008) 25-30.

[25] B.K. Körbahti, M.A. Rauf, Determination of optimum operating conditions of carmine decoloration by UV/H2O2, using response surface methodology, J. Hazard. Mater. 161 (1) (2009) 281-286.

[26] H. Jafari, S. Emami, Y. Mahmoudi, Numerical investigation of dual-stage high velocity oxy-fuel (HVOF) thermal spray process: a study on nozzle geometrical parameters, Appl. Therm. Eng. 111 (2016) 745-758. 


\section{Supplementary Materials}

\section{Derivation process of Eq. 1}

The motion of the disk is at all times based on a force balance. Deduced from Newton's second law, the following secondorder ordinary differential equation used to simulate the motion of the valve disk can be described as Eq. (S1):

$$
m_{\text {movable }} \ddot{y}_{\mathrm{t}+\Delta t}=F_{\text {flow }}+F_{\mathrm{c}}-F_{\text {spring }}-G_{\text {disk }}
$$

and $\mathrm{m}_{\text {movable }}$ and $\mathrm{G}_{\mathrm{disk}}$ can be written as:

$$
\begin{gathered}
m_{\text {movable }}=0.5 m_{\text {spring }}+m_{\text {spindle }}+m_{\text {disk-hoder }}+m_{\text {disk }}+m_{\text {bearing-seating }}+m_{\text {adjusting sleeve }} \\
G_{\text {disk }}=\left(m_{\text {spring }}+m_{\text {spindle }}+m_{\text {disk-hoder }}+m_{\text {disk }}+m_{\text {bearing }}+2 m_{\text {bearing-seating }}+m_{\text {adjusting sleeve }}\right) \times g
\end{gathered}
$$

where $m_{\text {spring }}, m_{\text {spindle }}, m_{\text {disk-holder }}, m_{\text {disk }}, m_{\text {bearing }}, m_{\text {bearing-seating }}$ and $m_{\text {adjusting sleeve }}$ are the masses of the spring, spindle, disk holder, disk, bearing, bearing seating and adjusting sleeve, respectively; $\ddot{y}$ is the acceleration of the moving part in the moving direction; $\dot{y}$ is the disk velocity; $F_{\text {flow }}$ is the force applied by flowing fluid; $F_{\mathrm{c}}$ is the force on the moving parts imposed by the accumulated steam in the back pressure chamber; $F_{\text {spring }}$ is the spring force acting on the disk.

The $\ddot{y}_{t+\Delta t}$ in Eq. (S1) can be discretized into discrete difference form:

$$
\ddot{y}_{\mathrm{t}+\Delta t}=\frac{\dot{y}_{\mathrm{t}+\Delta t}-\dot{y}_{\mathrm{t}}}{\Delta t}+\frac{\Delta t}{2} \cdot \ddot{y}_{\mathrm{t}+\Delta t}+H O T
$$

where $\Delta t$ is the time step defined in CFX. The velocity $\dot{y}_{t+\Delta t}$ can be further discretized as:

$$
\dot{y}_{\mathrm{t}+\Delta t}=\frac{y_{\mathrm{t}+\Delta t}-y_{\mathrm{t}}}{\Delta t}+\frac{\Delta t}{2} \cdot \ddot{y}_{\mathrm{t}+\Delta t}+H O T
$$

The lift of the disk $y_{\mathrm{t}}$ also appears in the expression for spring force:

$$
F_{\text {spring }}=y_{t+\Delta t} \cdot k_{\text {spring }}+F_{0}+F_{0.5}
$$

where $F_{0}$ and $F_{0.5}$ can be written as:

$$
\begin{aligned}
& F_{0}=\Delta y_{0} \cdot k_{\text {spring }} \\
& F_{0.5}=0.5 \cdot k_{\text {spring }}
\end{aligned}
$$

where $k_{\text {spring }}$ is the stiffness of spring; $F_{0}$ is the force applied by the steam on the disk at the set pressure; $\Delta y_{0}$ is the spring initial compression. The value of 0.5 is the initial lift to establish a continuous flow field at the first calculation step. The discrete form of the motion equation is re-assembled, and the disk displacement is finally isolated as: 


$$
y_{t+\Delta t}=\frac{F_{\text {flow }}+F_{c}-F_{0}-G_{\text {disk }}-F_{0.5}+\frac{2 m_{\text {movable }}}{\Delta t^{2}} y_{t}+\frac{2 m_{\text {movable }}}{\Delta t} \dot{y}_{t}}{\frac{2 m_{\text {movable }}}{\Delta t^{2}}+k_{\text {spring }}}
$$
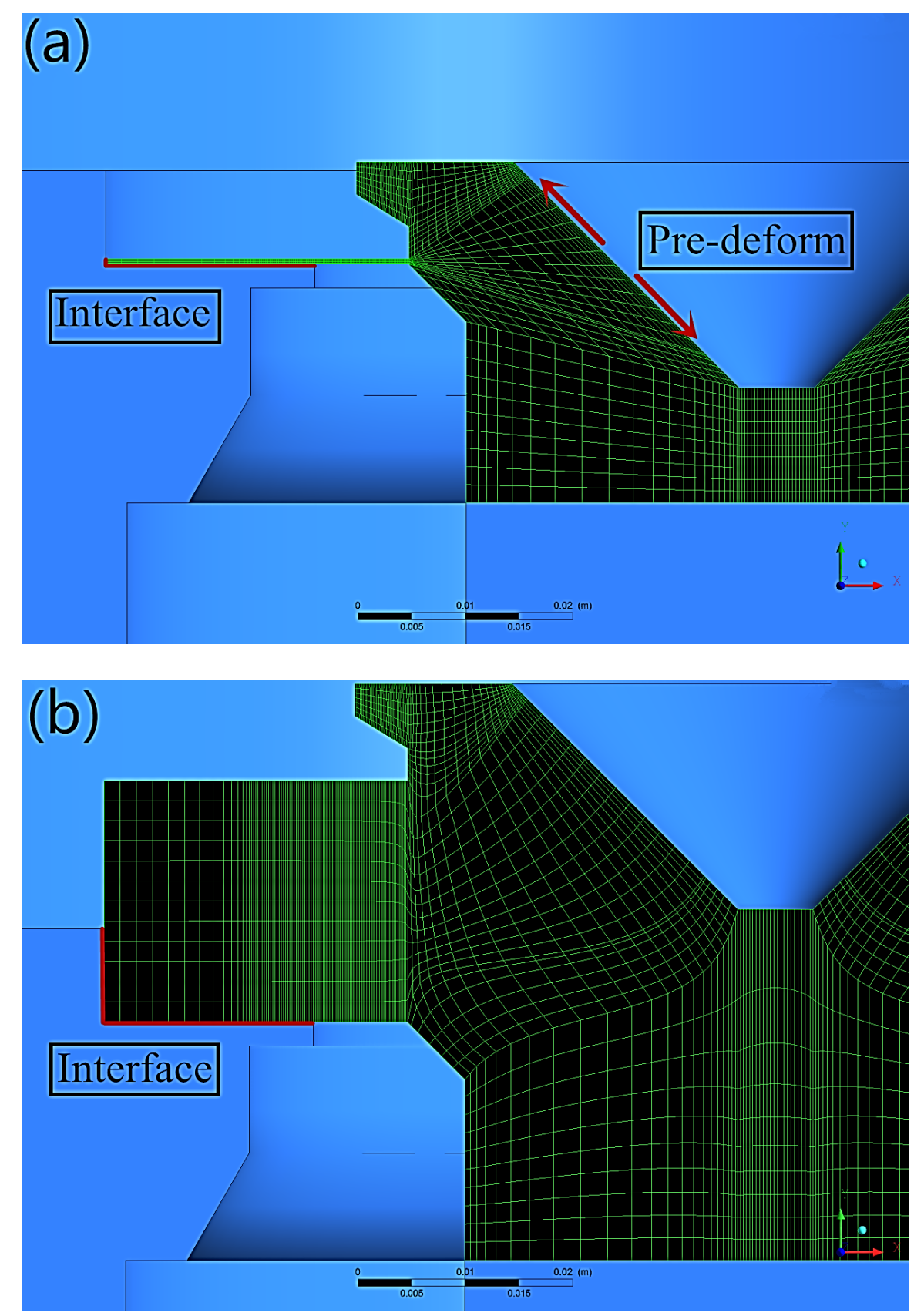

Fig. S1. Computational mesh in the crucial disk region at the minimum $(0.5 \mathrm{~mm})$ (a) and the maximum openings (b). 


Mach Number
4.0
3.6
3.2
2.8
2.4
2.0
1.6
1.2
0.8
0.4
0.0

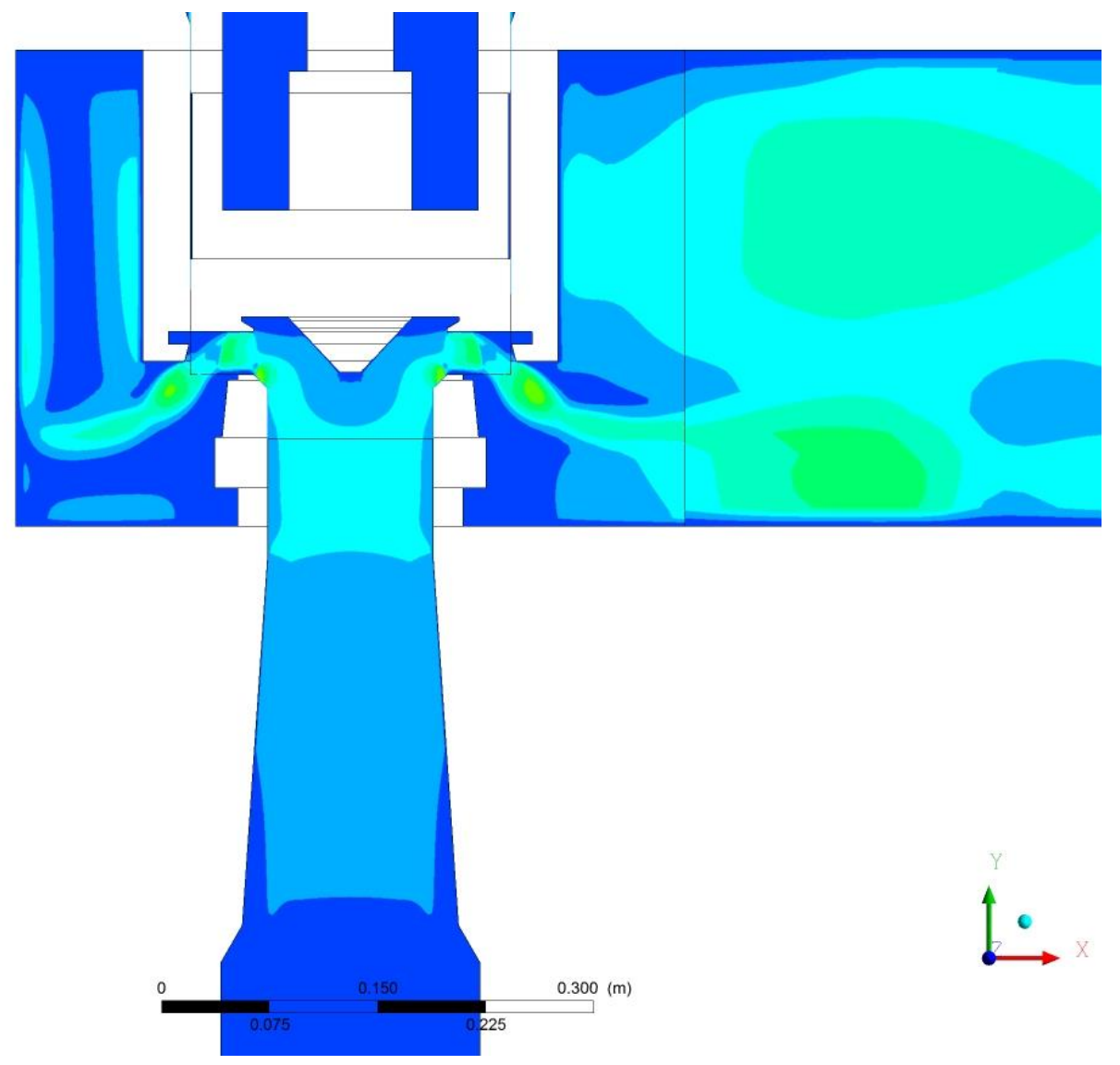

Fig. S2. Mach number contours on the symmetrical plane of throat area. $t=200 \mathrm{~ms}$. 